\title{
Case Study of a Complex Informing System: Joint Interagency Field Experimentation (JIFX)
}

\author{
William F. Murphy and Sandra Sanchez Murphy \\ University of South Florida, Tampa, FL, USA \\ wmurphy@usf.edu ssanche2@mail.usf.edu
}

\author{
Raymond R. Buettner, Jr. \\ Naval Postgraduate School, \\ Monterey, CA, USA
}

rrbuettn@nps.edu

\author{
T. Grandon Gill \\ University of South Florida, \\ Tampa, FL, USA \\ grandon@usf.edu
}

\begin{abstract}
The Joint Interagency Field Experimentation (JIFX) event, organized by the Naval Postgraduate School (NPS), is conducted 3-4 times a year at various locations. The four day event can be characterized as an informing system specifically designed to facilitate structured and unstructured communications between a variety of parties - e.g., software developers, inventors, military and civilian users of various technologies, academics, and agencies responsible for identifying and procuring technology solutions - that frequently are constrained in their informing activities in more restrictive venues. Over the course of the event, participants may observe technology demonstrations, obtain feedback from potential users, acquire new ideas about their technologies might be employed and, perhaps most significantly, engage in ad hoc collaborations with other participants.
\end{abstract}

The present paper describes an exploratory case research study that was conducted over a one year period and involved both direct observation of the event and follow-up interviews with 49 past participants in the event. The goal of the research was to assess the nature of participantimpact resulting from attending JIFX and to consider the consistency of the findings with the predictions of various theoretical frameworks used in informing science. The results suggest that participants perceived that the event provided significant value from three principal sources: discovery, interaction with potential clients (users) of the technologies involved, and networking with other participants. These findings were largely consistent with what could be expected from informing under conditions of high complexity; because value generally derives from combina-

Material published as part of this publication, either on-line or in print, is copyrighted by the Informing Science Institute. Permission to make digital or paper copy of part or all of these works for personal or classroom use is granted without fee provided that the copies are not made or distributed for profit or commercial advantage AND that copies 1) bear this notice in full and 2) give the full citation on the first page. It is permissible to abstract these works so long as credit is given. To copy in all other cases or to republish or to post on a server or to redistribute to lists requires specific permission and payment of a fee. Contact Publisher@InformingScience.org to request redistribution permission. tions of attributes rather than from the sum of individual attributes, we would expect that overall value from informing activities will be perceived even though estimates of the incremental value of that informing cannot be made.

Keywords: JIFX, informing system, complexity, disaster management, ad hoc experimentation, collaboration, military. 


\section{Introduction}

An axiom of informing science is that the underlying complexity of the informing to be accomplished will exert a significant impact on the structure of the informing system most appropriate to achieve the desired informing outcome. The Joint Interagency Field Experimentation (JIFX) event incorporates a design intended to achieve informing at an unusually high complexity level. The present paper describes an exploratory research case study intended to examine how the nature of JIFX, viewed as an informing system, facilitates and has adapted to the task of informing a highly diverse set of clients, including inventors, software developers, military personnel, disaster recovery personnel, vendors, government contracting agencies, and academics.

We begin with an introduction to informing systems theory, as it relates to complexity, and then examine the background and nature of the JIFX event. We then describe the methodology and report the results of a year-long research project that attempted to assess the consequences of past JIFX participation on a particular subset of clients: participants in the JIFX experiments. The results are then analyzed and the degree to which our observations of JIFX conform to, and extend, informing science are discussed and presented as a conclusion.

\section{Task Complexity and Informing Systems}

The nature and forms of task complexity have been recognized as being critical to achieving effective informing (Gill \& Hicks, 2006). It has been further argued that one of the most important factors influencing the structure of an informing system is the degree to which it is focused towards routine informing versus complex informing (Gill, 2009). The theoretical underpinnings of the case study are based in these two areas.

\section{Sources of Task Complexity}

Task complexity is a term that has eluded definition for many decades, despite a number of attempts to specify it (e.g., Campbell, 1988; Gill \& Hicks, 2006; Wood, 1986). The major challenge in dealing with the term is the ambiguous manner in which it has been used. For example, Gill and Hicks identified no fewer than 13 distinct definitions and usages of the term in the management and psychological literature that fell into five broad classes, shown in Table 1.

\section{Table 1: Task Complexity Classes}

\begin{tabular}{|c|c|c|}
\hline Name & Form of Definition & Example \\
\hline Experienced & $\begin{array}{l}\text { Task } \\
\text { Complexity } \rightarrow \\
\quad \text { Psychological state }\end{array}$ & $\begin{array}{l}\text { Example: If an individual perceives a task to be difficult, then } \\
\text { the task is complex }\end{array}$ \\
\hline $\begin{array}{l}\text { Information } \\
\text { Processing }\end{array}$ & $\begin{array}{l}\text { Task } \\
\text { Complexity } \rightarrow \\
\quad \text { IP Activity }\end{array}$ & $\begin{array}{l}\text { Example: If a task a task produces high information processing } \\
\text { (IP) levels, then the task is complex }\end{array}$ \\
\hline $\begin{array}{l}\text { Problem } \\
\text { Space }\end{array}$ & $\begin{array}{l}\text { Problem Space } \\
\text { Attributes } \rightarrow \\
\quad \text { Task Complexity }\end{array}$ & $\begin{array}{l}\text { Example: A task's complexity is defined by the minimum size } \\
\text { of the computer program required to perform the task. }\end{array}$ \\
\hline Structure & $\begin{array}{r}\text { Lack of Structure } \rightarrow \\
\text { Task Complexity }\end{array}$ & Example: The more routine a task, the less complex it is \\
\hline Objective & $\begin{array}{l}\text { Task } \\
\text { Characteristics } \rightarrow \\
\quad \text { Task Complexity }\end{array}$ & $\begin{array}{l}\text { Example: A task's complexity is determined by the number of } \\
\text { task elements, the degree of interrelationship between the ele- } \\
\text { ments and the degree to which task objectives are changing } \\
\text { (Wood, 1986). }\end{array}$ \\
\hline
\end{tabular}




\section{Three Domains of Task Complexity}

Gill (2010) later proposed that a sixth class, based on biologist Stuart Kauffman's (1993) notion of complexity leading to a rugged fitness landscape, was necessary. With this, complexity could be viewed as occurring in three overlapping domains: what is experienced by the task performer, the characteristics of the symbolic representation of the task, and driven by the actual behavior of the real world context in which the task is performed. These three domains (also referred to as dimensions) are depicted in Figure 1 (adapted from Gill \& Murphy, 2011) and listed in Table 2.

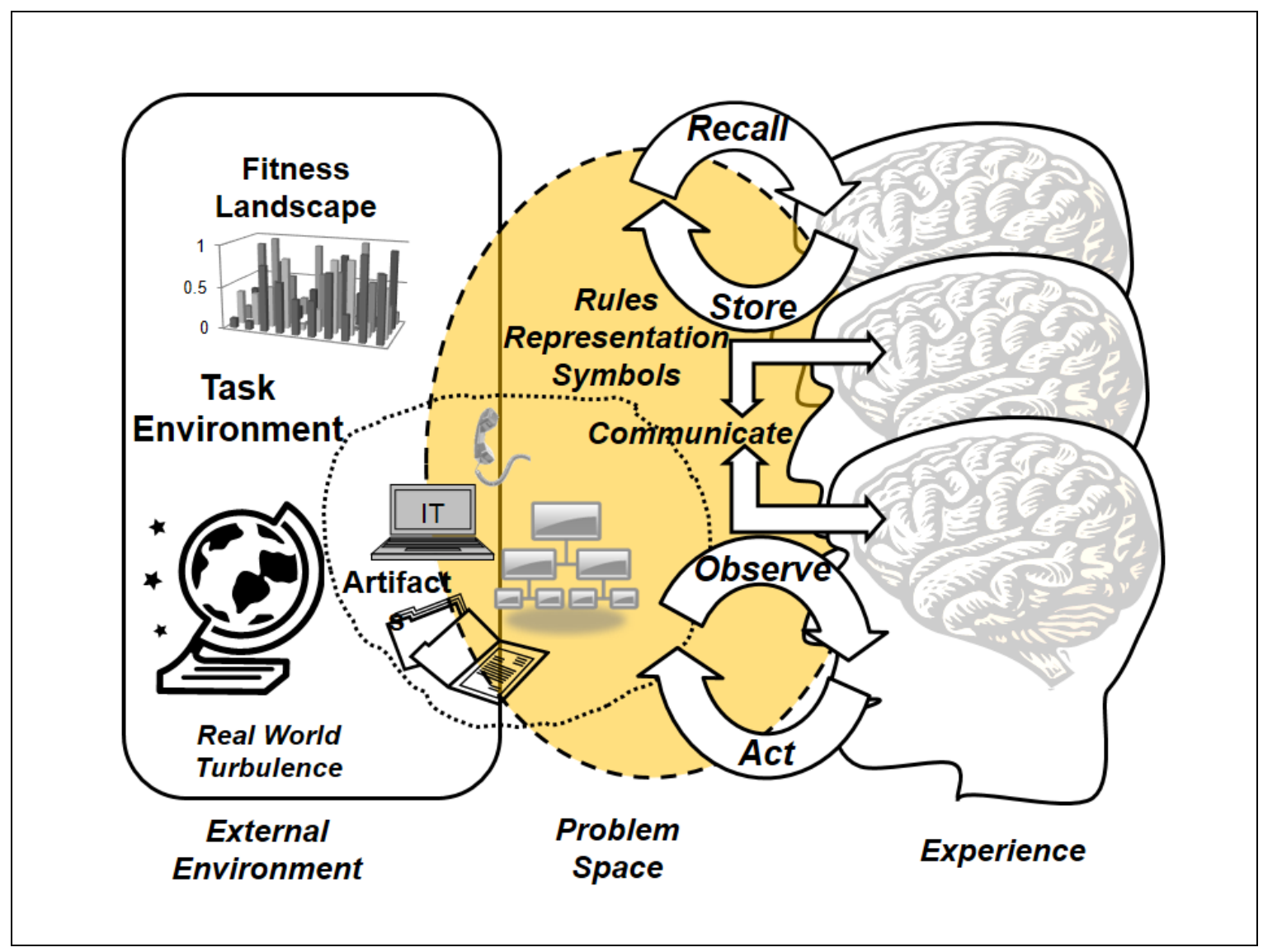

Figure 1: Three domains of task complexity

\section{Ruggedness}

The third domain, which deals with real world contexts, is particularly relevant when it comes to the design of informing systems. Complexity in this domain derives from two principal sources: ruggedness and turbulence. Ruggedness describes the degree to which the attributes that describe a task state interact in determining its fitness. Fitness, in turn, specifies the desirability of a particular state. In a biological context, fitness tends to be driven by successful reproduction across generations (Gill \& Hevner, 2011). In the context of a task, this might correspond to the degree to which a task performer attempts to return to a particular task state and the degree to which other performers seek the same state, perhaps as a consequence of imitation (Gill, 2012).

To clarify the concept of ruggedness, the contrast of a multiple-choice test and a cooking recipe can be a useful example. If we represent the attributes of a multiple choice test in terms of the responses to each individual question, then (in the typical test) each response will contribute to fitness independently. In other words, you will always get a better score if you get the right answer to a particular question, all other things being equal. 
Table 2: Dimensions of Task Complexity

(Hevner, Davis, Collins, \& Gill, 2014, p. 109)

\begin{tabular}{|l|l|l|l|}
\hline $\begin{array}{l}\text { Unfamiliar } \\
\text { (experienced } \\
\text { complexity): }\end{array}$ & Lack of structure & $\rightarrow$ & $\begin{array}{l}\text { Subjective experiences (e.g. } \\
\text { difficulty, uncertainty, ambigu- } \\
\text { ity) }\end{array}$ \\
\hline $\begin{array}{l}\text { Complicated } \\
\text { (problem space } \\
\text { complexity): }\end{array}$ & $\begin{array}{l}\text { Nature of problem } \\
\text { space (e.g. paths, } \\
\text { size) }\end{array}$ & $\rightarrow$ & $\begin{array}{l}\text { Information processing (e.g. } \\
\text { cycles, capacity) }\end{array}$ \\
\hline $\begin{array}{l}\text { Objectively Complex } \\
\text { (real world } \\
\text { complexity): }\end{array}$ & $\begin{array}{l}\text { Objective characteris- } \\
\text { tics (e.g. number of } \\
\text { elements, interrela- } \\
\text { tionships, dynamics) }\end{array}$ & $\rightarrow$ & $\begin{array}{l}\text { Ruggedness (e.g. number of } \\
\text { fitness peaks, sensitivity to } \\
\text { small change), turbulence (e.g. } \\
\text { punctuated equilibrium) }\end{array}$ \\
\hline
\end{tabular}

On the other hand, if - for the sake of simplicity - we represent each recipe in terms of the ingredients it contains, no such independence between attribute values exist. The contribution of garlic's presence or absence to fitness depends on the other ingredients in the recipe-it likely benefits nearly any dish whose main ingredient is lamb yet must be treated with suspicion in most recipes falling into the dessert category. As ruggedness grows, fitness becomes more and more dependent upon combinations of attributes rather than individual contributions of attributes. Moreover, with growing ruggedness attributing a certain percentage of fitness to a particular attribute begins to make less and less sense.

Ruggedness also tends to impact the statistical distribution of fitness across the landscape of combinations. Where a landscape is fully decomposable (i.e., each attribute contributes to fitness independently), as the number of attributes contributing to fitness grows, combinations of attributes selected at random from the landscape will tend towards a normal distribution. This is a direct consequence of the central limit theorem, taught in every introductory statistics course, since fitness is effectively determined by the sum of large number of independent variables.

For highly rugged landscapes, on the other hand, there is no compelling reason to assume fitness will be normally distributed, since the central limit theorem does not apply. To the contrary, other distributions where the distribution of fitness is heavily skewed towards a few states - such as those including a tail governed by the power law-are often observed (Gill, 2010). For tasks existing on such environments, traditional sampling techniques often fail to capture important combinations accounting for disproportionate percentage of the total pool of fitness.

\section{Task Complexity and Informing}

Framed in terms of task complexity, the informing process can be visualized as a transition from one fitness plateau to a new fitness plateau, as illustrated in Figure 2. The three issues that must be addressed in order to motivate change are as follows:

1. How familiar is the target state? We are unlikely to be motivated to leave our current fitness plateau if we are unsure about our destination or the path we must take to get there. Thus, we are more likely to undertake the journey if, for example, we have concrete examples to imitate. This is particularly true as ruggedness grows (Gill, 2012). Here the governing complexity is unfamiliarity.

2. How complicated is the planned journey? Moving from one fitness peak to another necessarily means transitioning through intermediate states of lesser fitness. For example, every golfer knows that the process of adopting a new golf swing necessarily involves a 
transition period where performance is lower than the starting state even if the end state is higher fitness. The same can likely be said of virtually any ERP implementation. Because plans exist primarily in symbolic form, this is largely an issue of problem space complexity.

3. What is the relative fitness of the end state? Unless we are convinced that the destination state is one of substantially higher fitness, the more rugged the landscape the less likely we are to consider the transition. The problem is much less severe on decomposable landscapes, since such landscapes necessarily consist of a single peak (Kauffman, 1993), and therefore incremental changes to reach that peak are usually accompanied by increasing fitness. In other words, high levels of ruggedness are normally accompanied by much deeper valleys between fitness peaks.

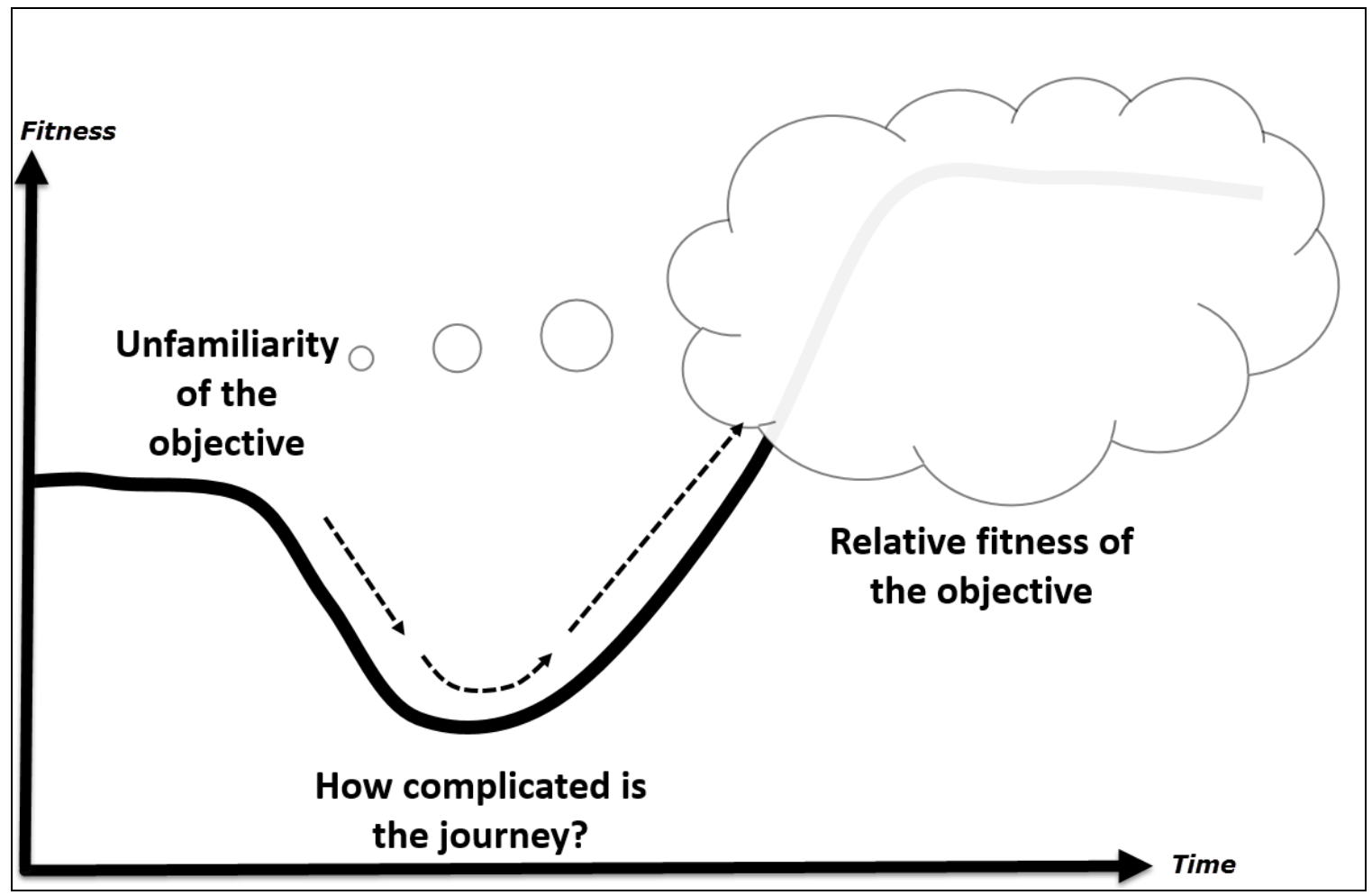

Figure 2: The informing process presented as a transition between two fitness plateaus

Effectively, this process can be viewed as a complementary perspective on Lewin's (1989) widely used planned model of change processes:

$$
\text { Unfreeze } \rightarrow \text { Move } \rightarrow \text { Freeze }
$$

In this interpretation, unfreezing is largely driven by unfamiliarity, moving is driven by complicatedness, and the difficulty of achieving subsequent freezing is driven by the relative fitness of the objective state (which may require substantial task performer practice before the fitness plateau is reached).

\section{Complexity and Informing System Structure}

The model presented in Figure 2 describes the process that an individual client must undergo when becoming informed about a new task or manner in which to perform an existing task. The ruggedness and dynamics of the fitness landscape similarly exerts a major influence on the design 
or evolution of informing systems intended to accomplish such informing. In attempting to synthesize the first decade of informing science research, twenty possible distinctions were observed. These are listed in Table 3.

Table 3: Differences between routine and non-routine informing systems (Gill, 2009)

1. Routine informing systems tend to be driven by the skills of the designer; complex systems evolve through cycles of interactions with stakeholders.

2. Routine informing systems tend to follow the informer $\rightarrow$ client model; complex systems involve flows between clients and across system boundaries.

3. Routine informing systems tend to have well defined structure and boundaries; complex systems tend to have neither.

4. Routine informing systems tend to map to a data $\rightarrow$ information $\rightarrow$ knowledge flow; complex systems exhibit patterns that are much harder to characterize

5. Routine informing systems tend to converge towards dedicated technologies and channels; complex systems tend to spread out across technologies and channels

6. The structure of routine informing systems tends to be driven by the task being performed; complex systems are organizationally situated and their structure cannot be predicted or explained without understanding the broader environment and the community of users.

7. The objectives of routine informing systems are based around the performance of a particular task or set of tasks; objectives in complex systems are much more closely related to client roles and the social context of informing.

8. Incremental informing normally leads to incremental improvements in performance for routine informing systems; in complex systems, incremental informing often results in misinforming.

9. The intended outcome of routine informing is normally purpose-focused activity; complex systems tend to support multiple, and often interrelated, goals.

10. Routine informing systems depend upon, and strive to instill, a specific mental model in the minds of clients; in complex systems, creating a specific model is not necessarily intended.

11. Routine informing systems support a specific goal or set of goals shared by all clients; complex systems tend to support a diverse, heterogeneous set of needs.

12. Routine informing systems tend to support task performance and efficiency; complex systems best support a need for adaptability.

13. Routine informing systems tend to perpetuate themselves; complex systems necessarily transform themselves.

14. Routine informing systems tend to be stable; complex systems migrate towards greater structure. 15. Routine informing systems adopt familiar communications patterns; complex systems continually seek a variety of patterns and paths for communications.

16. Routine informing systems have mechanisms for guaranteeing client attendance to the channel; for complex informing systems, client attendance is rarely assured.

17. Routine informing systems are robust in the presence of noise and minimally impaired by client filters; informing in complex systems can be degraded by noise and is heavily influenced by filters.

18. Routine informing systems will generally offer a variety of measures that can be used to assess system performance directly; the performance of complex systems will require indirect assessment approaches and will often require studying the historical and organizational context.

19. Routine informing systems tune themselves to particular fitness peaks; complex systems tend to support multiple peaks simultaneously.

20. Routine informing systems are particularly amenable to analysis grounded in logical empiricism; complex systems are better understood through adopting a hermeneutical-dialectic perspective.

As will become evident shortly, the JIFX event embodies many of the characteristics listed in Table 3 (in bold). Of particular interest is the role played by ruggedness and client diversity. Imagining the informing process as a transition by clients from one fitness peak to another-such as was presented earlier in Figure 2, if we look at the range of starting peaks and possible ending peaks we can conceive of the complexity of the informing task as being a function of these two 
variables. While the peak variables are clearly not dichotomous, for ease of visualization we can represent these in terms of four quadrants, as illustrated in Figure 3.

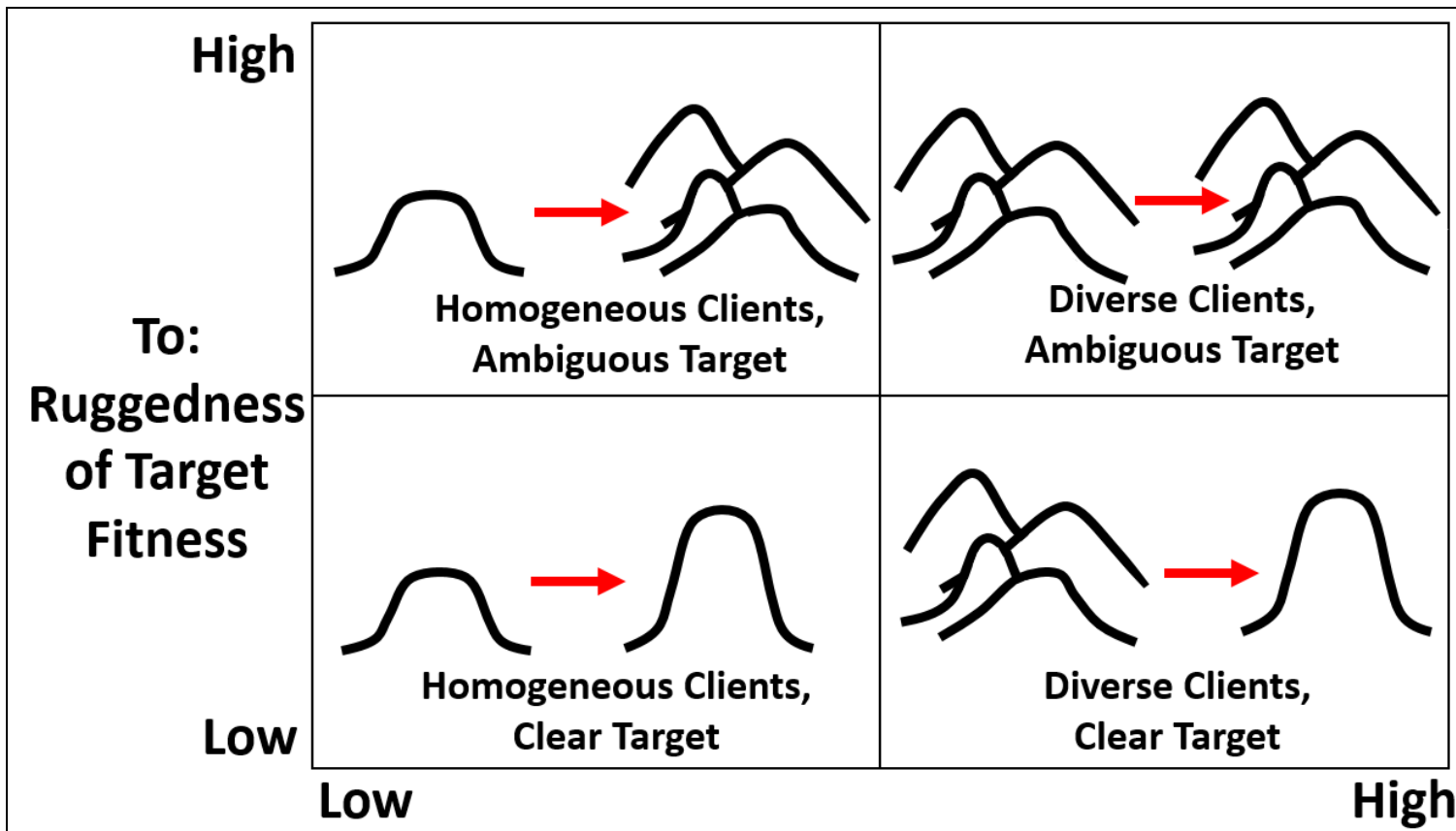

\section{From: Diversity of Initial Client Peaks}

Figure 3: Alternative complexity scenarios based upon client diversity and target ruggedness

Each of these informing scenarios is hypothesized to be best addressed by a system with different characteristics. For example:

1. Single Client-Single Target: Where a single client or a group of clients all coming in with nearly similar states of knowledge is present, the principal obstacle to informing is likely to be finding a path that minimizes the duration and loss of fitness associated with moving from one peak to another. Once found, informing should be effective through oneway channels from informer to client, such as a lecture, video, or manual.

2. Diverse Clients-Single Target: To be effective in this context, different paths to the target may need to be established to accommodate the needs of different clients. For example, in a classroom context a self-paced structure incorporating alternative versions with text and video might be offered or alternative versions of the same class might be designed with students being given the option to choose (e.g., Gill \& Jones, 2010). Where a routine system is developed to accommodate such diversity of paths, it will necessarily be very complicated. Many institutional systems - such as the tax code or the health care system-attempt to achieve this type of informing.

3. Single Client-Multiple Targets: Sometimes, an informing context occurs where the goal is to move participants to consider, and perhaps pursue, alternative peaks. For example, such a context might occur where a prevailing paradigm is failing or where groupthink has set in. An example of such a system might involve bringing in a group facilitator to encourage thinking "outside of the box" using techniques such as brainstorming.

4. Diverse Clients-Multiple Targets: By far the most complex context, this scenario requires a combinatorial explosion in the number of paths that need to be considered. For exam- 
ple, if clients exist on $\mathrm{M}$ fitness peaks and the system seeks to move them to $\mathrm{N}$ alternative peaks, potentially $\mathrm{M}$ x N paths may need to be developed. Of necessity, the clients themselves will need to be heavily engaged in adaptively mapping out their own learning paths, any formally designed system that efficiently moves clients along a sensible path would quickly become too complicated to sustain itself. In addition, the large number of local peaks associated with rugged landscapes tends to limit the feasibility of algorithmic approaches, such as multi-objective decision analysis, that tend to require enumeration of possible alternatives (Keller, Simon, \& Wang, 2009).

Given the need to engage clients in their own learning in the last of these scenarios, the venue developed for informing is likely to play a critical role in the system's effectiveness. The JIFX event, which we now describe, represents precisely such a venue.

\section{The JIFX Event}

The specific context for the current investigation was the Joint Interagency Field Experimentation (JIFX) program, organized by the Naval Postgraduate School. To understand the JIFX program and the individual field events described, it useful to consider the program's evolution, stated goals and underlying philosophy.

\section{Evolution of the Event}

The JIFX program evolved to its current form over a period of approximately 10 years. In 2002 the Naval Postgraduate School (NPS) initiated a series of field activities intended to provide NPS students and faculty the opportunity to demonstrate and evaluate new technologies in a field environment while allowing the military's operational community to explore and experiment with these technologies. The first events focused on a single challenge, the use of unmanned aerial vehicles to improve the rescue of downed pilots (Oros, 2014). In 2003, motivated in part by the thesis work of NPS students, the events began to focus on the "integration of a tetherless transmit/receive link(s) between soldiers, tactical vehicles, ground sensors, manned and unmanned platforms to push/pull secure voice, data and video" (Manuel, Murphy, \& Paxton, 2004.) The focus on the need for a dynamic and flexible network was sufficiently complex that each experiment now involved multiple threads and participation was expanded to include industry and other government research entities. These events attracted funding from the United States Special Operations Command (SOCOM) and were originally known as STAN (Surveillance and Target Acquisition Network) and in 2004 the name changed to TNT (Tactical Network Topology) as the focus of the field events continued to broaden in scope. These early events more closely resembled routine informing systems in that they each had specific challenges to be addressed and the emphasis was on finding technical solutions.

From 2004 to 2007 the program was still narrowly focused on specific topics and did not involve large numbers or a large variety of organizations. From 2007 through 2009 the program, incorporating regular quarterly field events, increased in size and scope while enjoying steady funding from a variety of sources such that each event included hundreds of participants from dozens of organizations all working on a growing number of increasingly complex challenges. It is toward the end of this period that the collaborative impact, first identified as enabling interagency synergy development is formally recognized (Bordetsky \& Netzer, 2010). It is the recognition of this synergy, and the potential of the events as powerful informing systems, that leads to the formalization of the processes and structure of the events. To explore the potential of these events as informing systems a conscious effort was made to broaden both the nature of the challenges and the community of interest that would be engaged to address same. Focusing on humanitarian assistance and disaster relief (HADR), RELIEF (Research and Experimentation for Local and International Emergency and First-responders) events were conducted immediately prior to TNT 
events. These events demonstrated that the collaboration and synergy was not limited to military and government problem sets or participants and led to the classification of this type of information system as multi-institutional semi-structured learning environments (MISSLE) where participants were both clients and informers by design (Buettner 2013). The events continued to grow in size and scope and evolved to reflect the attributes of complex informing systems. This evolution into a complex informing system led to the end of TNT/RELIEF, as the primary sponsor was unable to justify in simplistic budget terms the emphasis on shared learning as opposed to technology development and acquisition. The last TNT/RELIEF event was conducted in June 2013. These events supported hundreds of theses and academic publications and sent dozens of technologies to the battlefield (Oros, 2014.)

JIFX was initiated during the last year of TNT/RELIEF and was designed to address a continually evolving set of complex challenges affecting a diverse group of stakeholders. Its primary purpose is educating the participants, not acquiring capabilities.

\section{JIFX Goals}

As described in its funding documents, JIFX is intended to address the need for more aggressive integration and innovation in the pre-acquisition environment to improve requirements generation and acquisition system performance with a primary objective being to more effectively use defense dollars. As described by a JIFX organizer:

JIFX addresses the systems and challenges associated with more rapidly and efficiently fielding innovative capabilities using a proven informing process constantly tuned to address various important problem domains identified by the stakeholders with an emphasis on the providing the stakeholders with the solutions required for future mission sets. This effort incorporates appropriate interagency resources as well to ensure the broadest applicability and increased efficiencies in both discovery and application. These increased efficiencies include shorter time to delivery, reduced risk and reduced cost. These are the product of the unique collaborative environment and interactive dialogue that is created by the quarterly field events. These events lead to more dynamic interaction between the war fighters, scientists, and engineers that both inform requirements and leverages nongovernment (corporate) development dollars.

In short, JIFX was designed to inform problem holders regarding the potential solutions space while, at the same time, informing solution providers regarding the problem (opportunity) space with the goal of creating more efficient outcomes for all parties. JIFX reflects many of the attributes identified as associated with complex informing systems in Table 3.

\section{JIFX Philosophy}

Central to the conduct of each JIFX event was a philosophy that encouraged unplanned (ad hoc) collaborations, prized learning from failures, and emphasized knowledge sharing. In order to achieve maximum interaction JIFX was conducted in a non-acquisition environment, no sales or similar activities being permitted. All information exchange was unofficial, that is all participants represented only themselves and any opinions offered were considered to be personal and not representative of the participant's organization. Restricted information sharing (classified, proprietary, etc.) was discouraged to avoid exclusion. Since the goal was to learn there were no penalties for failure in the achievement of any particular experimental objective. Daily briefings, where everyone offers a quick overview of their effort, highlighted participants whose reach exceeded their grasp. In addition to formal evaluations by various participants, each experiment 
was assessed by the performers and all evaluations were shared with the stakeholders- -with each experimenter able to see all comments regarding their efforts.

As described on the JIFX website, the events were austere by design, bounded but not controlled, inclusive by default, collaborative, and immediate.

\section{JIFX Participants}

As shown in Figure 4, the 251 participants of one recent JIFX event (August 2014) consisted of representatives of 6 major constituencies. They represented 82 distinct organizations. On the government side, in addition to the Combatant Commands (stakeholders) and Department of Defense representatives, the Department of Homeland Security, the Department of State, the National Guard Bureau, the National Reconnaissance Office, and the National Geospatial Intelligence Agency were represented.

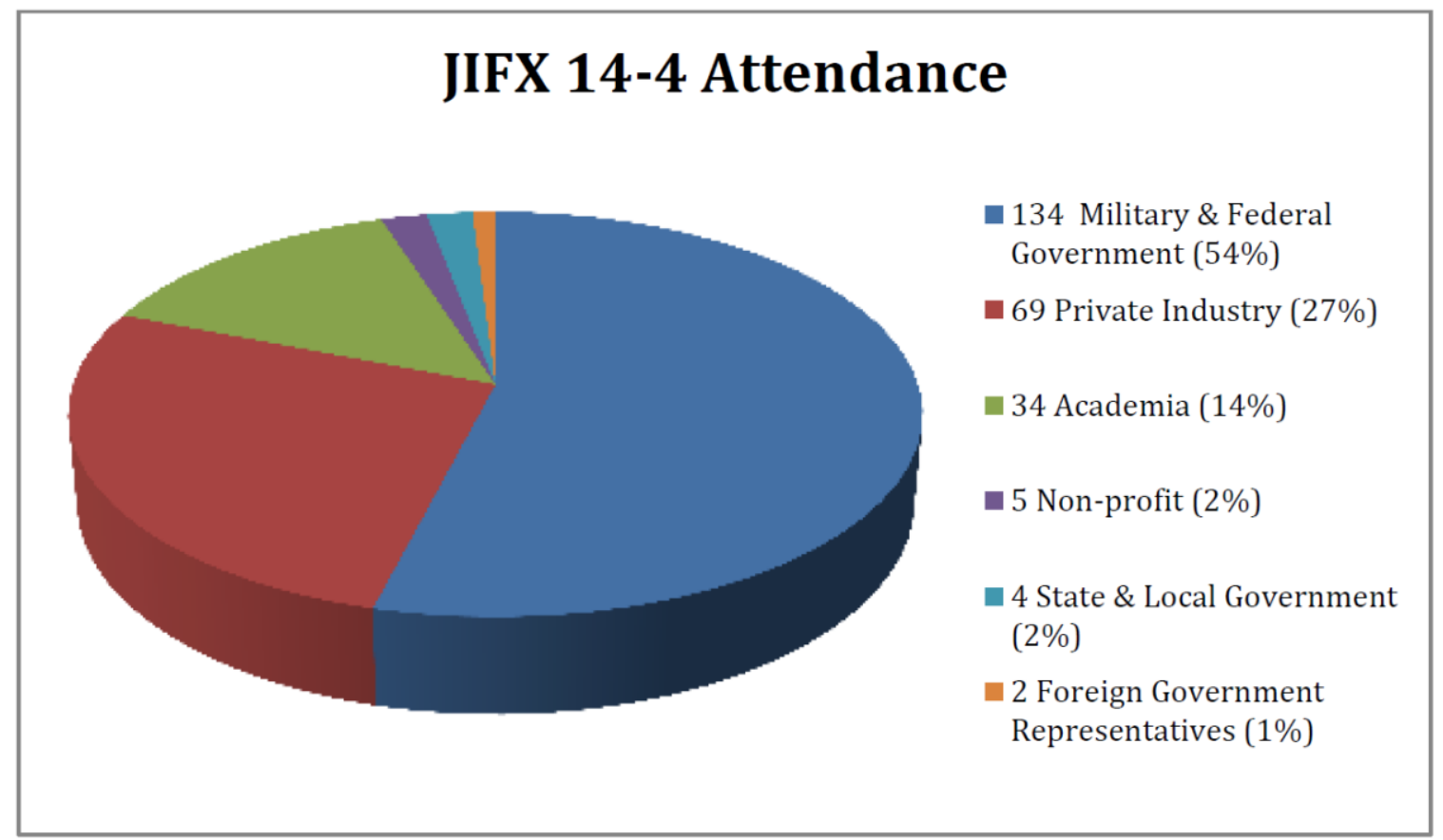

Figure 4: JIFX Participant Breakdown

State and local governments were represented by the California Governor's Office of Emergency Services, Sacramento County Office of Emergency Services, and the San Luis Obispo County Fire Department.

Representing the academy were Stanford University, Carnegie Mellon University, Arizona State University, New Mexico Institute of Mining and Technology, California State University Long Beach, Georgia Tech Research Institute, University of South Florida, and from Germany, the Ludwig Maximilian University of Munich and Bundeswehr University Munich.

Industry and non-profit participation ranged from corporate giants such as Cisco, Lockheed Martin, and Northrop Grumman to small privately held firms such as Babel Street and NGOs such as Team Rubicon.

This diverse group conducted, evaluated, and collaborated for the conduct of more than 30 planned experiments over a three day period at Camp Roberts National Guard facility in central California. 
Murphy, Murphy, Buettner, \& Gill

\section{JIFX Structure}

The JIFX process consisted of pre-event activities, event execution and post-event activities. During the events themselves the goal was to have just enough structure to be safe, secure, and legal so as to minimize potential barriers to collaboration.

In the pre-event processes stakeholders (clients) with challenges identified their respective problem domains and solicited the assistance of government, industry, and academic experts (informers) that may have knowledge regarding potential solutions to these challenges. This solicitation was done in the form of a Request for Information posted on the FedBizOps.gov website. Responses to this solicitation were provided via the JIFX website and were formatted into information charts (commonly referred to as quad charts) and white papers.

A panel of stakeholders reviewed solicitation responses describing the proposed solutions and invited participation in a quarterly JIFX field event based on the panel's assessment of the potential solution described. By this point in the process, the JIFX design had already initiated bidirectional informing flow regarding the problem domain and potential solutions between the client and informer.

The stakeholders developed a list of activities, designated "experiments" to reflect the failure tolerant learning centric nature of the event, intended to explore the potential of the proposed solutions. These experiments could vary from a narrow and isolated proof of concept to a complex scenario incorporating moving vehicles, complex communications, and active adversaries.

During the event phase dozens of respondents and interested observers would typically participate in the field event. Industry participants were permitted only if conducting experimentation, and even those groups were composed of engineers and scientists with the attendance of marketing personnel (or marketing activity) prohibited. Events were open for all United States government employees, and a typical event had dozens of government agencies represented (not part of the stakeholder/client group) that attended to be informed regarding the state of technologies that may be useful to them as well. The social networking and transactive memory enhancement that one would normally see at a conference or trade show also took place at these events.

These experiments tended to be focused on new technologies but, as previously noted, the event was not an acquisition activity but rather a learning activity. The stakeholder clients were focused on learning about potential capability solutions and not the purchase of any particular widget. The conduct of the experiments served as a focused channel for more engaged communications between the client and informer, again in both directions.

Finally, post event, a variety of written reports were produced to include a stakeholder's assessment, specialized reports (such as cyber security assessments), and a formal after action report. The later typically exceeded 200 pages in length and represented a participant provided, stakeholder edited, record of each experiment (in addition to the comments of any evaluators). The full final report was restricted to government entities to avoid any appearance of endorsement but each participant could view the sections of the report that addressed the experiment that they conducted.

\section{Research Questions}

The research questions to be addressed in the study fell into three categories:

1. Questions specific to the exercise that sought to identify potential sources of value realized from the exercise, and

2. Questions that specifically related to the broader area of the design and effectiveness of informing of the JIFX informing processes. 
3. Meta-questions relating to informing under conditions of complexity.

\section{Source of Value Specific Research Questions}

Prior to the study, a considerable amount of anecdotal evidence had been amassed that participants - of all categories - perceived value was being realized in the exercise. Based on an initial visit to the exercise, made prior to the funding of the research, the principal investigator initially postulated sources of value that included the following:

1. Accelerated defect detection. Within the world of software testing and design science, it has long been recognized that early detection of defects or shortcomings in an artifact reduces cost. Many JIFX activities involved taking components from different sources and mashing them together. The "willingness to fail" that characterized JIFX encouraged participants to subject their products to public tests and experiments that quickly surface undiscovered product limitations. By detecting these early in the product lifecycle, total product cost would likely be reduced. This source of value would most likely be realized by product developers.

2. Costs of substitute products. Many of the artifacts used at JIFX events were low-cost substitutes for existing technologies, e.g., off-the-shelf cameras taped to unmanned aerial vehicles (UAVs), explosive holding containers built with low-tech, readily-available materials. This source of value would most likely be realized by participants involved in acquisitions.

3. Cost-shifting of product refinement. When innovative artifacts are first introduced, several cycles of refinement may be required before they are optimized for the needs of a particular user. In the case of products for government use, it is common for the government to contract for and bear the cost of these refinements. The informing system employed by JIFX was designed to encourage companies to rethink their products and, on their own initiative (and at their own expense), refine them to make them more attractive. This source of value was expected to be realized by two types of participants: participants involved in acquisitions, who would experience reduced contract costs, and product developers through increased likelihood of eventual purchase of their product.

4. Time reduction. Along the lines of the previous item, the interactions encouraged by JIFX seemed likely to accelerate the process of development. This represents a contribution to the value side of the equation, since the benefits of the artifacts developed should be realized earlier. This source of value, once again, was predicted to be realized by participants involved in acquisitions and by product developers.

5. Improved design fitness. The fitness of a particular artifact design describes its ability to evolve and improve over time (Gill \& Hevner, 2011). While the immediate usefulness of the artifact contributes to this, so do other factors, such as malleability (ability to be retasked by end users), openness to inspection, and novelty. This source of value would be particularly relevant to the end-user (e.g., disaster recovery personnel, war fighters), the most likely beneficiary of improved design. Factors such as decomposability, malleability, and openness may also enhance the likelihood that the product developer will be able to sell the product eventually.

As the study evolved, the scope was narrowed to a particular subset of participants - product developers - leading to a series of research questions most likely to be relevant to this group of participants: 
- Does participation in JIFX lead to accelerated defect detection?

- Does participation in JIFX lead to accelerated product improvements?

- Does participation in JIFX lead to improved product or system design?

\section{Informing-Specific Research Questions}

One of the most intriguing aspects of the JIFX design was the many possible informing flows that could occur between participants. Even accepting the limitation that product/system designers were to be the central focus of the study, informing flows could occur:

- Between product developers

- Between product developers and experts (e.g., academic and domain experts)

- Between product developers and end-users (e.g., disaster recovery personnel and war fighters)

- Between product developers and potential customers (e.g., individuals or organizations involved in acquisition; other vendors).

In addition, informing could occur through casual networking, product demonstrations, or over the course of the planned or ad hoc experimentation that was central to the JIFX event.

This led to a broad series of research questions of the form:

- Does a product/system developer derive value from interactions with potential customers?

- Does a product/system developer derive value from interactions with potential vendors of other products or services?

- Does a product/system developer derive value from interactions with potential users of the product or service?

- Does a product/system developer derive value from interactions with experts in the area?

- Does a product/system developer derive value from viewing demonstrations of related products, processes, or services?

- Does a product/system developer derive value from networking with individuals being encountered for the first time?

- Does a product/system developer derive value from networking with prior contacts?

- Does a product/system developer derive value from participating in ad hoc experiments?

\section{Informing Meta-Questions}

The value-specific and informing-specific questions addressed in the research were further influenced by the possibility that the fitness of JIFX outcomes could well be characterized by a rugged landscape. This would imply challenges resulting from two key aspects of the event:

1. Exercise participants were quite heterogeneous, even after the study was limited to product/service developer participants. These types of solutions being developed included (but were not limited to) software, high-tech hardware, low-tech hardware, integrated systems, and novel processes at various stages of maturity. The nature of the participants also varied considerably, including (but not limited to) small businesses, large businesses, defense contractors, academic researchers, and military personnel. 
In a rugged informing environment, there would be little reason to expect that different participants would achieve fitness through the same types of informing processes.

2. Fitness on a rugged landscape does not lend itself to decomposition. In other words, any attempt to apportion value to different informing sources would tend to run into the same type of earlier-mentioned problem that we encounter when trying to determine the relative contribution of the ingredients in a recipe.

This leads to a couple of meta-research questions:

- Does the perceived value of different JFIX informing channels vary significantly by the type of product/service being considered and by the nature of the participant?

- Are the JIFX participants able to provide well-articulated apportionments of value to alternative informing sources?

If the answer to the first of these questions is yes, then that would support the proposition that JIFX presents a rugged fitness landscape to participants. If participants are consistently able to identify the value associated with specific informing channels, on the other hand, this would be consistent with a more decomposable, less rugged fitness landscape.

\section{Research Design}

The research design can be characterized as exploratory case research, relying heavily on triangulation of data sources, which included interviews, archival data, survey, and direct observation. As is typical of an exploratory case research process (Gill, 2011), data gathering include both planned and opportunistic elements.

\section{Research Phases}

The design involved four phases:

1. Pre-Proposal: Prior to the commencement of the project, the principal investigator (PI) observed a JIFX exercise held at Camp Roberts, in California, in August 2012.

2. Proposal: Based on the observations made during the pre-proposal phase, the PI prepared a research proposal and interview protocol based around the research questions presented in the previous section. The project was funded in August 2013 but, owing to a U.S. Government shutdown that occurred during the fall, the JIFX event that was intended to kick off the project in November 2013 was cancelled.

3. Data Gathering: The PI, and two graduate assistants sat in on a modified JIFX eventfocused on social media and held online - in November 2013, then conducted a series of pilot interviews. In February 2014 the three attended a JIFX event in California to observe and conduct face-to-face interviews. During the period from February-July 2014, the graduate assistants conducted phone interviews of past JIFX participants. In August 2014 the PI attended one additional JIFX event in California, taking the opportunity to interview past participants who attended that event. All data was entered into an MS Access database for subsequent analysis.

4. Analysis and Write-up: During the period from August-October 2014, the information collected in the database was analyzed and provided to the event organizers at the Naval Postgraduate School, who conducted a final check for factual accuracy. 
Murphy, Murphy, Buettner, \& Gill

\section{Data Gathering}

Participants in the JIFX event were selected based upon white paper submissions. As of May 2014, 252 separate white papers could be identified referencing experiments that had actually been conducted. A typical white paper was between 2000 and 2500 words and summarized the proposed experiment.

Effectively, this represented all past JIFX participants and was used as the principle means of identifying appropriate interview candidates. A separate database entry was created for each experiment. In addition, tables were created to record interview results for each experiment.

To contact interview candidates, the project team relied on email lists provided by the event organizers at the Naval Postgraduate School. Emails were sent to each participant in order to set up a time for a phone interview with the project's graduate assistants. That email also included a link to an optional survey that respondents could fill out in advance to reduce interview time (included as Appendix A). Later, because of the difficulty in acquiring phone interviews, that survey became the primary tool for data gathering.

In addition to the phone interviews, the PI and graduate assistants conducted interviews with many past participants at two JIFX events, the first of which (February 2014) was attended by the entire team and the second (August 2014) attended by the PI.

\section{Interview protocol}

Systematic surveys were conducted using telephone interviews of current and former JIFX and TNT participants in an effort to determine the impact - both qualitative and economic - of the event on the development and adoption of participating technologies.

The interviewing process took place between September 2013 and August 2014. It involved examining a database of 313 white papers that described experiments/projects that were conducted at JIFX events from 2012-2014 and interviewing participants to assess subsequent outcomes of participation in JIFX. Forty-nine interviews (done by phone, in person and/or through use of a survey) were obtained through the data gathering process.

The interview process was initiated by sending a pilot test of emails. The pilot test consisted of sending emails for 10 of the projects from past JIFX events. The emails described the research and included a link to the online survey. A PDF version of the survey was also included so respondents could review the questions prior to survey or interview. The survey consistent of a series of coded questions. Because many participants had several projects and participated in multiple events, a copy of the white paper of interest was also attached to the email. Out of the pilot emails sent, two surveys were completed, and two interviews were completed. Interviews covered any questions that were not answered in the initial email survey with the addition of several openended questions that were not included in the survey.

After the initial pilot test of emails, JIFX coordinators sent an email to past participants informing them that they would receive an email request for participation, the nature of the research, and encouragement to participate.

Email requests were then sent out for the remaining 232 projects that had identified email addresses. No changes in content or protocol were made to the email process identified for the pilot test. The emails were sent out in five batches with a week or two between each batch. Each batch represented an event date and was sent out in order of oldest first. This was done to allow participants from the most recent event to realize the full benefits of the event (i.e., networking, project evolution) prior to being interviewed. A follow up email was sent to all participants that indicated a willingness to participate in a follow up interview to request a mutually agreeable time. At this point in the interview process, all interviews were conducted via phone. Email requests resulted 
in 21 completed interviews, and 12 completed project surveys without interview. These numbers include the results from the pilot test.

Two weeks after all emails were sent, cold calling was conducted for the participants that did not respond to the emailed survey but had an available phone number. Interviews for 11 projects were completed as a result of cold calling.

\section{Follow-up face-to-face interviews}

Towards the conclusion of the project, the principle investigator attended the June 2014 JIFX event and was able to obtain surveys for an additional five projects. The PI described the nature of the research and asked participants of past events that were in attendance to complete the online survey.

\section{Results}

In order to address the research questions of the studies, results from the interviews were numerically tabulated by participant and experiment type. Interview comments and observations were also manually examined to look for specific examples of participant informing.

\section{Respondent Profiles}

A total of 49 interviews were conducted. The breakdown of these interviews is as follows:

- 23 completed the online form. Of these:

○ 2 chose not to be interviewed subsequently

- 4 could not be contacted subsequent interviews

- 17 were interviewed by phone or face-to-face subsequently

- 26 were interviewed by phone or face-to-face only

Given 252 experiments in the database (that were not cancelled for one reason or another), this represents a $19.5 \%$ response rate.

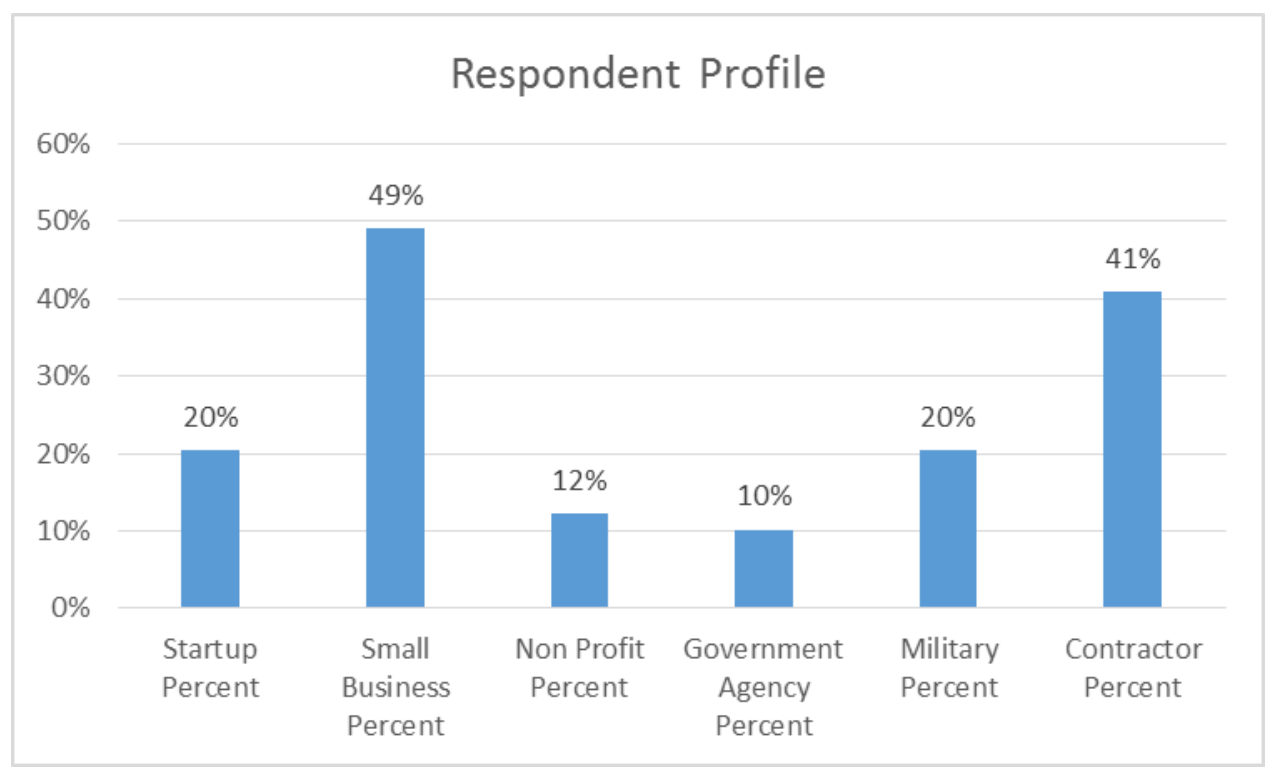

Figure 5: Where interview participants came from

Realistically, this understates the actual response rate, for two reasons: 
1. Many experiments continued over multiple JIFX events, but our protocol treated these as one-time experiments.

2. Many experiments were conducted by the same individual within the same organization. To avoid undue inconvenience to past participants (as well as repetition of many questions), we limited ourselves to a single interview per participant. Otherwise, we would have expected double-counting on questions such as those relating to the perceived organizational benefits of JIFX.

Based on these qualifications, an adjusted assessment of the response rate would be 36 organizations out of 146 total participating organizations (25\%). Participant organizations and experiment types are summarized in Figures 5 and 6 respectively. Because a participant could fall into multiple categories, the percentages do not add to $100 \%$.

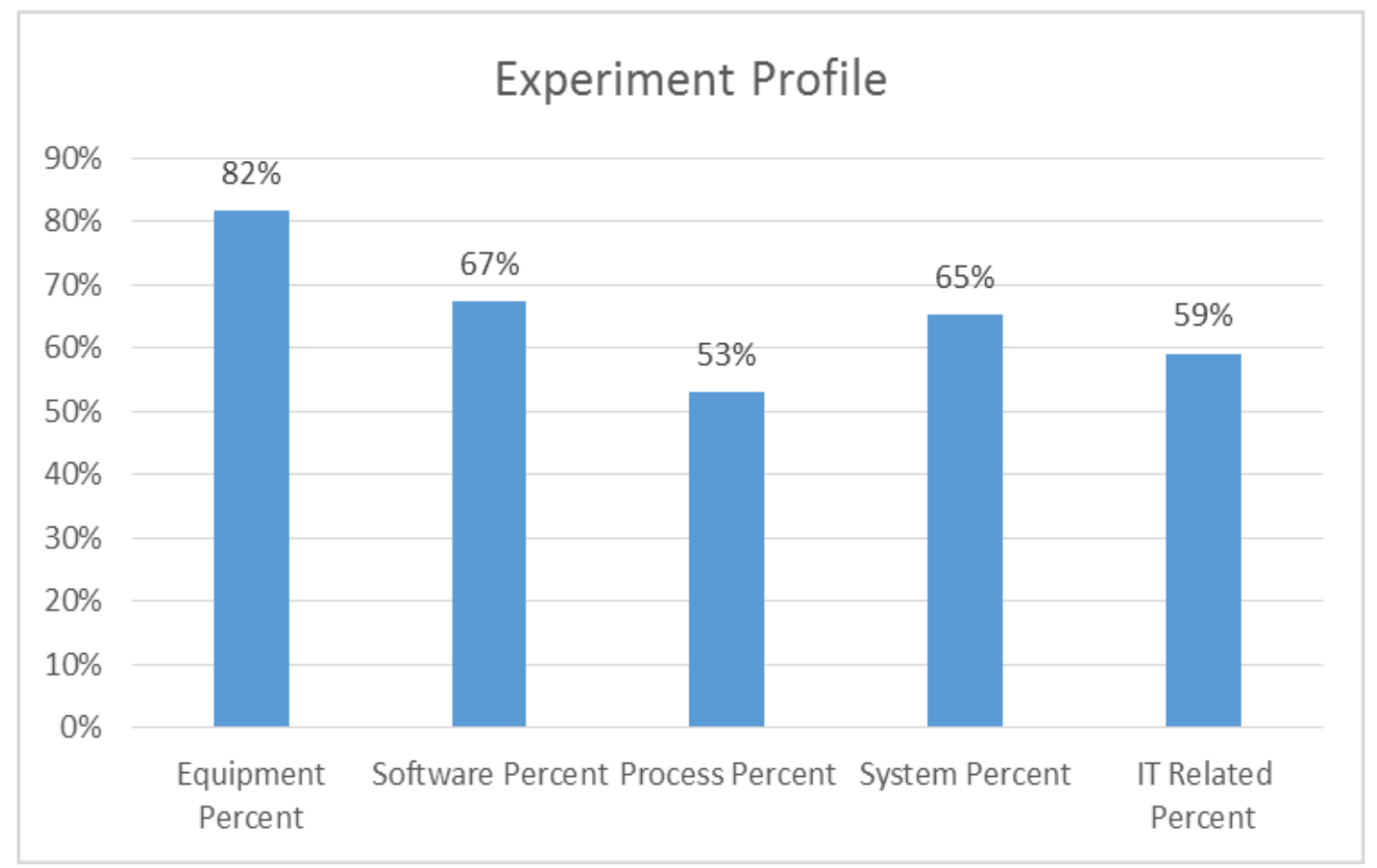

Figure 6: Types of experiments

A more detailed data summary table of participants and outcomes is presented as Appendix B.

\section{Overall Perceptions of Value}

As indicated in Figure 7-which rates the overall value of the event on a scale of 1 (little or no value) to 5 (extremely great value) - participants rated the event highly, further supported by the fact that almost $80 \%$ of the respondents planned to attend another JIFX event.

\section{Perceived Value by Informing Type}

Based on the interview findings, it was clear that participants found value from JIFX based upon a number of sources, as illustrated in Table 4.

As a rough approximation, any difference between two of these means that is greater than 0.4 is likely to be significant at the 0.05 level (assuming equal standard deviations). Based on this, it is evident that the greatest sources of informing value were perceived from: 
- Making new contacts

- Interactions with potential users of the product, process, or service

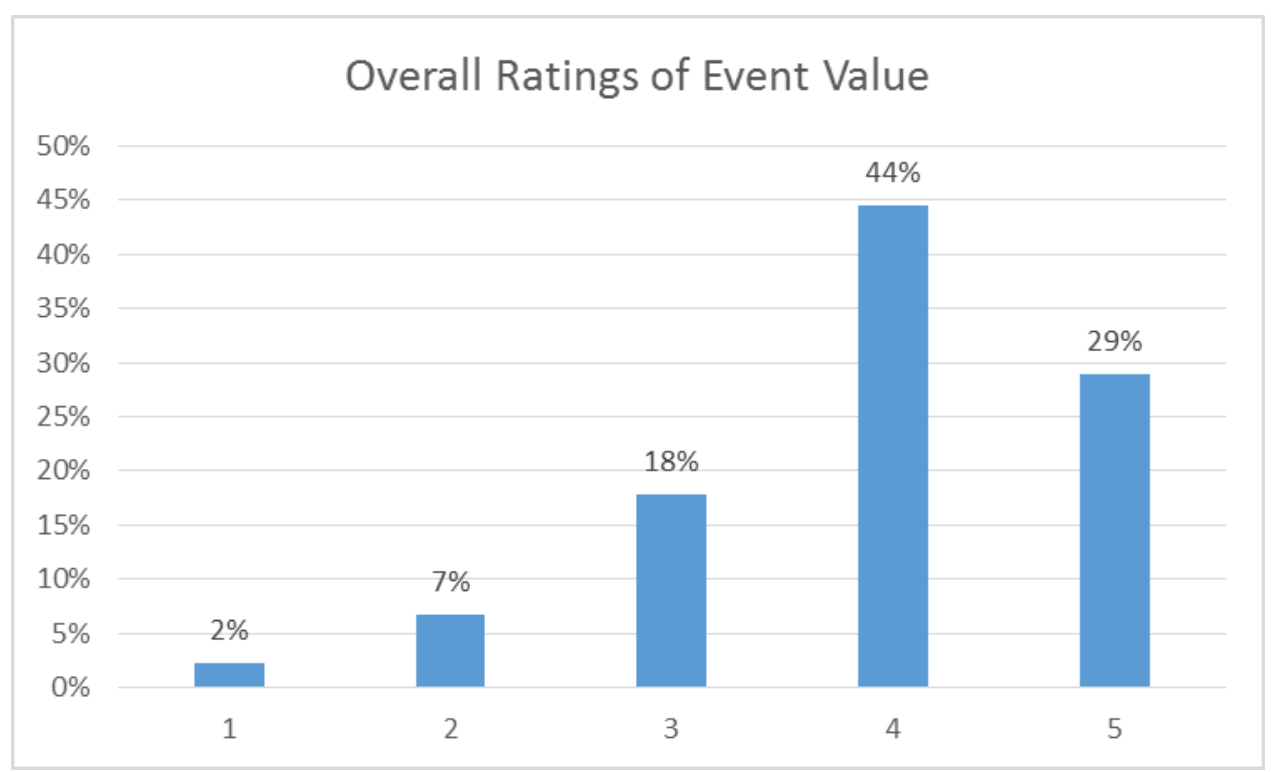

Figure 7: Overall perceptions of JIFX event value ( $1=$ little or no value, $5=$ extremely great value)

Table 4: Perceived Sources of Value by Informing Type

\begin{tabular}{|l|c|c|c|c|c|c|}
\hline \multicolumn{1}{|c|}{ Source of Value } & $\begin{array}{c}\mathbf{1}=\text { Little } \\
\text { or no } \\
\text { Value (or } \\
\mathbf{0 = N} / \mathbf{A})\end{array}$ & $\begin{array}{c}\mathbf{2}= \\
\text { Minor } \\
\text { Value }\end{array}$ & $\begin{array}{c}\mathbf{3}= \\
\text { Some } \\
\text { Value }\end{array}$ & $\begin{array}{c}\mathbf{4}= \\
\text { Considerable } \\
\text { Value }\end{array}$ & $\begin{array}{c}\mathbf{5}= \\
\text { Very } \\
\text { Great } \\
\text { Value }\end{array}$ & Mean \\
\hline $\begin{array}{l}\text { Meeting potential cus- } \\
\text { tomers }\end{array}$ & $16 \%$ & $4 \%$ & $31 \%$ & $31 \%$ & $18 \%$ & 3.31 \\
\hline $\begin{array}{l}\text { Meeting potential ven- } \\
\text { dors of other products } \\
\text { or services }\end{array}$ & $15 \%$ & $19 \%$ & $19 \%$ & $38 \%$ & $9 \%$ & 3.06 \\
\hline $\begin{array}{l}\text { Meeting potential users } \\
\text { of the product or ser- } \\
\text { vice }\end{array}$ & $4 \%$ & $4 \%$ & $22 \%$ & $42 \%$ & $27 \%$ & 3.82 \\
\hline $\begin{array}{l}\text { Meeting experts in the } \\
\text { area }\end{array}$ & $19 \%$ & $13 \%$ & $19 \%$ & $29 \%$ & $21 \%$ & 3.21 \\
\hline $\begin{array}{l}\text { Viewing demonstra- } \\
\text { tions of related prod- } \\
\text { ucts, processes or ser- } \\
\text { vices }\end{array}$ & $17 \%$ & $21 \%$ & $21 \%$ & $32 \%$ & $9 \%$ & 2.94 \\
\hline $\begin{array}{l}\text { Networking with prior } \\
\text { contacts }\end{array}$ & $17 \%$ & $11 \%$ & $20 \%$ & $35 \%$ & $17 \%$ & 3.24 \\
\hline $\begin{array}{l}\text { Networking with new } \\
\text { contacts }\end{array}$ & $2 \%$ & $7 \%$ & $17 \%$ & $33 \%$ & $41 \%$ & 4.04 \\
\hline
\end{tabular}


These two sources were not mutually exclusive. Moreover, at least some participants perceived high value from every informing channel. This likely reflects the highly heterogeneous nature of participants in the event. These findings were consistent with the qualitative analysis.

A particularly interesting question is where the participants who judged JIFX most valuable found the greatest value. To assess this, we grouped the value sources according to the total JIFX value question (scored on a 1-5 scale) and looked at where the greatest perceived changes of value occurred as overall value rose.

What Table 5 illustrates is a pattern whereby the value in each informing category appears to rise with total value - a not-very-surprising result (value levels with a very low number of responses are greyed out).

Table 5: Value Perceptions of Participants Perceiving High Overall JIFX Value

\begin{tabular}{|c|c|c|c|c|c|c|c|c|}
\hline 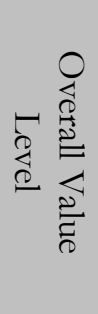 & 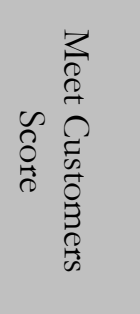 & 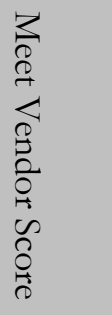 & 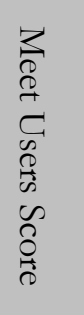 & 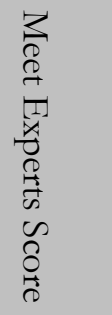 & 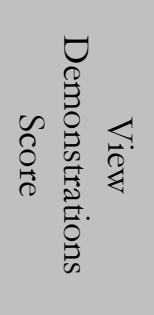 & 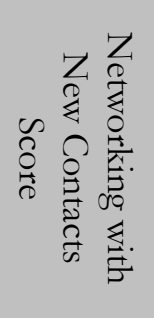 & 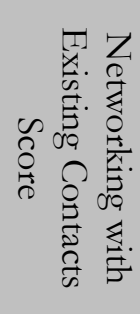 & 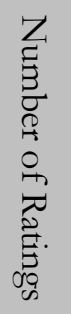 \\
\hline 1 & 5.00 & 2.00 & 5.00 & 4.00 & 4.00 & 5.00 & 5.00 & 1 \\
\hline 2 & 4.00 & 2.33 & 3.33 & 3.00 & 3.00 & 3.33 & 1.33 & 3 \\
\hline 3 & 2.88 & 2.63 & 3.13 & 2.50 & 2.13 & 3.50 & 2.75 & 8 \\
\hline 4 & 3.20 & 2.70* & 3.80 & 3.25 & 2.75 & 4.00 & $3.00 *$ & 20 \\
\hline 5 & 3.35 & $3.76 *$ & 4.24 & 3.29 & 3.29 & 4.12 & 3.82 * & 17 \\
\hline
\end{tabular}

There are two categories where value contributions between the top two levels of overall perceived value change significantly:

- Meeting vendors

- Networking with existing contacts

Stated in terms of likely causality, respondents who derived value from interactions with vendors and past contacts seemed to derive unusually high value from JIFX.

\section{Summary of Participant Type Results}

A tabulation of perceived informing value by participant type is presented in Appendix C. With 6 different participant types and 8 tests per participant, a total of 48 significant tests were conducted. If the data were randomly distributed, we would expect 2-3 significance values with $\mathrm{p}<0.05$, which happens to be what was observed. This is consistent with the proposition that any impact between participant type and informing benefits must occur through interaction with other factors. This would be consistent with a complex informing scenario.

\section{Summary of Experiment Type Results}

A tabulation of perceived informing value by experiment type is presented in Appendix C. With 4 different experiment types and 8 tests per type, a total of 24 significant tests were conducted. If the data were randomly distributed, we would expect $1-2$ significance values with $p<0.05$, while 4 were actually observed - all of which barely passed the $5 \%$ significance test. This is consistent 
with the proposition that any direct impact between experiment type and informing benefits is minor, at best, and that key differences are more likely to occur through interaction with other factors. Once again, this would be consistent with a complex informing scenario.

\section{Informing Value of Ad Hoc Collaborations}

A major element of the JIFX design was the encouragement of ad hoc collaborations between participants. To assess whether substantial differences in perceived informing patterns between different types of experiments existed, a simple T-test to compare the means value between experiments of a particular type and the remainder of the sample was conducted.

The perceived values of ad hoc collaborations are presented in Table 6. Experiments involving these collaborations appeared to derive greater benefits from meeting experts than other types of experiment. This effect was the largest observed in all the comparisons conducted and may well be the only direct effect that should not be dismissed as a result of predictable random variation or minor, at best. It would also appear to make sense, as expertise in the technologies or processes being studied would likely be a critical prerequisite of such undertakings.

Table 6: Ad Hoc Collaborations Other Experiment Value Assessments

\begin{tabular}{|c|c|c|c|c|c|c|c|c|c|}
\hline & 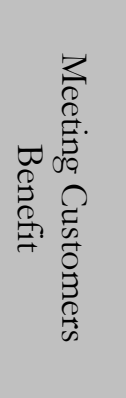 & 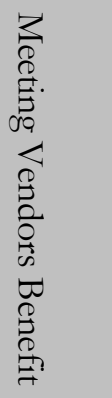 & 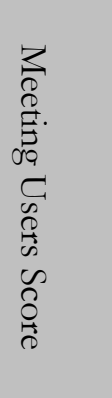 & 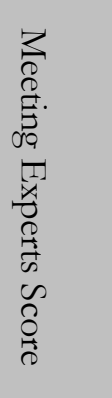 & 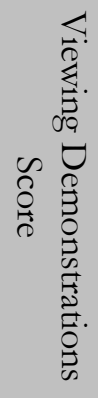 & 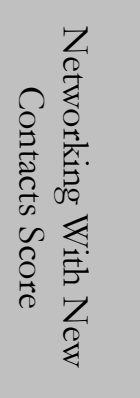 & 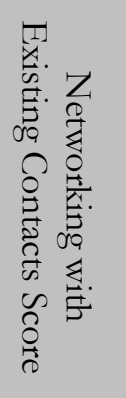 & 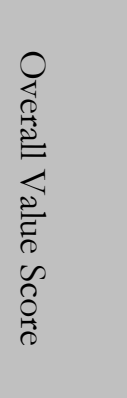 & 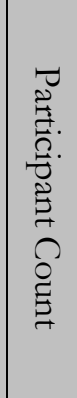 \\
\hline Ad hoc collaborations & 3.41 & 3.00 & 3.88 & 3.44 & 3.00 & 4.03 & 3.12 & 4.03 & 34 \\
\hline Other experiments & 3.00 & 3.07 & 3.73 & 2.47 & 2.60 & 3.73 & 3.33 & 3.93 & 15 \\
\hline T-statistic & 1.11 & -0.18 & 0.40 & 2.62 & 1.08 & 0.80 & -0.58 & 0.26 & \\
\hline P-value & 0.27 & 0.86 & 0.69 & 0.01 & 0.29 & 0.43 & 0.56 & 0.80 & \\
\hline
\end{tabular}

\section{Qualitative Results}

An important reason for performing a labor-intensive interview-based research protocol was to triangulate structured response data (such as presented in Appendix C) with specific examples from respondents. The qualitative analysis element of the case study focused on identifying such examples. Some of these are now considered in the context of the three categories of research question.

\section{Value specific research questions}

When prompted to describe sources of value from JIFX, a number of respondents referred to the direct benefits postulated for the JIFX events. The specific questions and some quotes from respondents follow:

Does participation in JIFX lead to accelerated defect detection?

Experiment 35: "It [JIFX] is very valuable for testing our new technologies prior to release." 
Experiment 94: [What do you see as the principal sources of value from JIFX?] "Relatively low cost, low hassle means of testing equipment... in a relevant environment with real end-user hands-on testing and feedback. Relatively low-cost, high-fidelity, means of demonstrating the capability to govt agencies in a venue where they have a high confidence that the testing is realistic due to the participation of the JIFX experimentation team."

Experiment 163: "It is a great test environment and opportunity to focus on field use in semi-realistic conditions. Feedback and interaction is great added bonus."

Experiment 164: [What do you see as the principal sources of value from JIFX?] "Ability to test and demonstrate new technologies in a forgiving environment."

Experiment 198: "We appreciate the opportunity to experiment, fail, tinker and witness collaboration toward solving real world problems. The environment fosters this and everyone is comfortable with those conditions knowing that iteration, evolution and breakthroughs can happen at JIFX rather than in a real-world situation."

Experiment 241: "The thinking has evolved. It has opened up Pandora's box, a lot more questions than answers...I tagged onto the social media experiment. A lot of what we wound up doing was throwing out what we had planned, and instead figured out what we wanted to do. We all got together and discussed what the needs are of the decision makers, especially as they relate to social media."

\section{Does participation in JIFX lead to accelerated product improvements?}

Experiment 186: In 2013, we looked at some of the various technologies and some of the tools that we might want to use in the field. Things that could keep a record or what we had done, where we had been, and tracking of our personnel for safety purposes. We asked a couple of people that had come in with their tools to do a mashup and just demonstrate some different use cases for how their technology could be molded in a way that might be beneficial for us and our specific usage...If JIFX didn't exist, the mash-ups would have never occurred and I would not have been exposed to the wide variety of tools and software out there. Just being there in general was very beneficial.

Experiment 256: "When we first went to JIFX it was a standalone LTE solution. The first JIFX allowed us to experiment with satellite and carrier egress. The second JIFX we were able to test those in a planned way. I believe there is another JIFX coming up in a maritime locations, and we want to get some experience with a maritime application because that is a little different from the land based ones we have had so far...Getting feedback from DOD and homeland security and public safety figures had been very useful in tuning the product we think the world wants. JIFX takes a month's worth of being on the road and mashes into a couple of days."

Experiment 261: "We are in constant development. The most important thing we got from JIFX in terms of how we improved our software was the Joint Vulnerability Assessment branch they were able to give us some great security tips on how to improve the architecture, so we have since incorporated all of those and all of their write ups into our app...”

Experiment 273: "After JIFX, we took the feedback that we receive. We adjusted the system a little bit. We took it to a demo in Virginia Beach, and got some more user feedback there. We are now evaluating where to invest going forward with it."

Experiment 281: "As a direct result of being at JIFX, we have had a lot of various communications with COCOMs [combatant commands] and additional communications with 
DHS [Department of Homeland Security] and other companies and well. Many of these interactions have prompted us to make various technology enhancements or feature enhancements."

Does participation in JIFX lead to improved product or system design?

Experiment 25: "Note to financial impact: Hundreds of thousands of dollars because of feedback to the developers, so we aren't going down the wrong track with our design."

Experiment 42: "We made some design changes to the product we built at the JIFX and we were able to validate those changes and we did it. Based on what we learned there, we made some more changes and that made it even better."

Experiment 127: "It was great to get that input from JIFX because it completely changed my design generation cycle. It changed the whole way I was looking at designing my product, and I changed a lot of things all based off of JIFX experiment."

Experiment 226: "We got a better sense of what the users and other participants were expecting from our product that we were developing, so we made a lot of refinements in that sense."

In contrast to these examples, when given the opportunity to cite specific sources of valuewhich should have been easier to recall, being more concrete-respondents were surprisingly vague and had very little to say. Examples of the comments in this area include:

Experiment 12: "Met some people from dept of state. Resulted in a small sale."

Experiment 245: "JIFX participation provided access to funding."

Experiment 301: [Description of how JIFX impacted the (product, process, service)] "We were able to make more sales"

\section{Informing specific research questions}

The study design was such that the principal source of evidence for informing flows was the structured survey questions. There were, however, a number of comments made during interviews that further supported the value of various types of informing. Nearly all these responses came in answer to the question:

What do you see as the principal sources of value from JIFX?

For example:

Experiment 34: "Very rare location where we get to meet the people from government and understand their needs and we also have a chance to meet other people who are working to support the government. Between all of that we figure out how we fit in."

Experiment 37: "Potential networking with engaged stakeholders."

Experiment 44: "Technology exposure for both developers and potential users. Ability to obtain potential customer feedback on design considerations, competing technologies and interest."

Experiment 52: "Spontaneity, esprit-de-corps, collaboration"

Experiment 127: "JIFX gave me the opportunity to get feedback from other folks about my product. I really made a lot of connections as far as getting outside viewpoints. We are computer and explosive experts, so we have a very set way of looking at things sometimes." 
Experiment 149: "Invaluable to be able to meet with and experiment with end users. Commercial and government contacts that are sometimes are just conversations and other times are mashup ad-hoc experiments. Those interactions are invaluable. The knowledge that we gained in networking. From 2013, we continue to be in contact with folks from NSA and the Department of Energy. With that we have done some engineering, pre-sales consultations. Both of the times we have gone, we came away with ongoing relationships that are very valuable. That is among the most important reasons we hope to/plan to go back."

Experiment 186: "Being exposed to different technology and seeing how they could work for us, but I also really appreciate the people who come and the organizations that attend. It is really nice to meet up with them in an environment that is outside of their normal because sometimes we can make a better relationship or partnership or learn more about an organization that way."

Experiment 198: "The ability for us to integrate and collaborate with virtually any / all other experiments at any one event given the need and focus on field work. The application of our technology, expertise, processes can both benefit other collaborators but more importantly, feedback and the experience itself helps guide and shape our technology roadmap."

Experiment 233: "It [JIFX] is a big networking opportunity, and it also helps us to guide our product and get some relevant feedback that helps us tailor our product to meet the needs of the user."

Experiment 264: "It has given us invaluable contacts and helped us to navigate through a very large and complicated bureaucracy by putting a human face on the equation. Providing a secure venue to exhibit, test and demonstrate new technologies is of significant value to inventors concerned with I.P. issues."

Experiment 287: "Getting together with everyone and being able to understand the use cases."

Experiment 290: "JIFX provides a collaborative experimentation venue that has given our company additional insight into the potential consumers requirements. It also provides us with a looking glass of technologies that may be delivered in the future. This insight provides us with possible areas where our technology may be useful in coming years"

Experiment 299: "You don't know what is needed, required, what is out there, how you could enhance other people's stuff as well as what other offerings you have. With our engineering team, we can go back to them and say FEMA is looking for this or military is looking for this, or a way to get to this point. It benefits us to keep informed of what is out there, what needs to be out there, and what solutions they are looking for."

\section{Informing meta-questions}

The qualitative component of the study was particularly well-suited to addressing the second of the research meta-questions, namely:

Are the JIFX participants able to provide well-articulated apportionments of value to alternative informing sources?

Specifically, respondents were given an opportunity to specify a value (or cost) associated with participation in the JIFX event, and then to provide an explanation (see questions 23-25 of Appendix A). Out of 49 responses, only one numerical response was made - and that was a cost associated with a participant that did not see any value. 
There are many reasons why we would not expect every respondent to provide a value - e.g., some existed in positions or at levels in organizations that probably lacked exposure to cost and marketing data, some experiments involved technologies, systems, or processes so embryonic that any such estimate would have been pure speculation, some might have withheld such information for proprietary or competitive reasons, and so forth. Nevertheless, it seems remarkable to acquire no concrete estimates of value in a survey of an exercise where:

1. $73 \%$ of the respondents indicated that the event was of considerable or great value

2. Nearly $80 \%$ of respondents indicated that they planned to return to another iteration of the event

A much more plausible explanation is that the question itself is one that cannot be answered in a reasonable way, much like the question of the "value" of baking powder to the fitness of a cake. And, as discussed in the earlier review of complexity, this is precisely what we would expect on a complex fitness landscape.

\section{Analysis}

In order to address the research questions, some additional exploratory analysis was required. These further results were then triangulated with qualitative results from the interviews.

\section{Types of Informing}

The interview and online questionnaire administered to JIFX participants was very specific with respect to different informing sources. An interesting question to consider was whether these sources would naturally cluster into more general informing categories. To explore this question, a principle component analysis was conducted, the results of which are presented in Table 7.

Table 7: Three Factor Principle Component Results

\begin{tabular}{|c|r|r|r|}
\hline \multicolumn{5}{|c|}{ Rotated Factor Loadings } \\
\hline Variables & Factor1 & Factor2 & Factor3 \\
\hline Customers & -0.096 & $\mathbf{0 . 8 8 6}$ & 0.217 \\
\hline Vendors & $\mathbf{0 . 7 6 1}$ & 0.238 & 0.012 \\
\hline Users & 0.296 & $\mathbf{0 . 8 1 2}$ & -0.254 \\
\hline Experts & $\mathbf{0 . 8 2 9}$ & -0.001 & 0.256 \\
\hline Demonstrations & $\mathbf{0 . 5 9 7}$ & -0.067 & 0.438 \\
\hline Networking-Prior & 0.214 & 0.033 & $\mathbf{0 . 8 8 1}$ \\
\hline Networking-New & $\mathbf{0 . 8 5 8}$ & 0.039 & 0.108 \\
\hline Analysis performed with Free Statistics Software (Wessa, 2014) \\
\hline
\end{tabular}

The best fit was achieved with three factors and suggested three reasonably distinct types of informing were being observed:

- Discovery (Factor 1): Key contributors were meetings with vendors, experts, observing demonstrations and networking with new contacts.

- Client-Driven Informing (Factor 2): Key contributors were customers and users.

- Relationship Maintenance (Factor 3): Mainly impacted by networking with old clients. 
$74 \%$ of all variance was explained using the three factors. The proportion of variance explained by each factor was $0.48,0.29$ and 0.22 respectively.

A four factor model was also tested. The results appeared to split the "Discovery" factor into two components as follows:

- Technology Discovery (Factor 1): Key contributors were meetings with vendors, experts, and networking with new contacts.

- Client-Driven Informing (Factor 2): Key contributors were customers and users.

- Technology Analysis (Factor 3): Key contributors were meetings with experts and product demonstrations.

- Relationship Maintenance (Factor 4): Mainly impacted by networking with old clients.

The factor loadings are presented in Table 8:

Table 8: Four Factor Principle Component Analysis

\begin{tabular}{|c|r|r|r|r|}
\hline \multicolumn{6}{|c|}{ Rotated Factor Loadings } \\
\hline Variables & Factor1 & Factor2 & Factor3 & Factor4 \\
\hline Customers & -0.109 & $\mathbf{0 . 9 3 2}$ & 0.112 & 0.099 \\
\hline Vendors & $\mathbf{0 . 7 9 3}$ & 0.15 & 0.171 & 0.107 \\
\hline Users & 0.478 & $\mathbf{0 . 7 4 1}$ & -0.157 & -0.16 \\
\hline Experts & $\mathbf{0 . 5 7 4}$ & 0.003 & $\mathbf{0 . 6 7 6}$ & 0.114 \\
\hline Demonstrations & 0.183 & 0.021 & $\mathbf{0 . 8 9 4}$ & 0.129 \\
\hline Networking-Prior & 0.184 & 0.01 & 0.15 & $\mathbf{0 . 9 6 4}$ \\
\hline Networking-New & $\mathbf{0 . 8 1 6}$ & -0.041 & 0.305 & 0.174 \\
\hline Analysis performed with Free Statistics Software (Wessa, 2014) \\
\hline
\end{tabular}

$84 \%$ of all variance was explained using the three factors. The proportion of variance explained by each factor was $0.33,0.25,0.25$ and 0.18 respectively.

Although the variance explained by the three factor model was slightly below the $80 \%$ threshold recommended, the cleaner loadings of that model (i.e., expert informing was not split between two factors) made it preferable to the four factor model. It should be noted that, given the nature of the data gathering process, either model should be viewed as exploratory-suggestive of a particular conceptual scheme rather than being taken as strong empirical support for a particular set of hypotheses.

\section{Sources of Overall Informing Value}

One important informing-related question with respect to the complexity of the JIFX would be determining if any particular type of informing contributed directly to perceived overall value. Treating the perceived overall informing value of the exercise corresponds as an estimate of fitness, we would predict that respondents would have difficulty separating out the value of separate informing channels.

Two approaches - both exploratory in nature-were used to assess the degree to which contributions of different types of informing to overall perceived value were tested. The first involved using multiple regression of the different types of informing against the overall perceived value of JIFX. These results, presented in Figure 8, show no individual forms of informing appear to contribute to overall value at a statistically significant level. 


\begin{tabular}{|c|c|c|c|c|}
\hline \multicolumn{2}{|c|}{ Regression Statistics } & & & \\
\hline Multiple R & 0.482220963 & & & \\
\hline R Square & 0.232537057 & & & \\
\hline Adjusted R Square & 0.122899493 & & & \\
\hline Standard Error & 0.916817677 & & & \\
\hline \multirow[t]{3}{*}{ Observations } & 49 & & & \\
\hline & & Standard & & \\
\hline & Coefficients & Error & t Stat & P-value \\
\hline Intercept & 2.532008376 & 0.657017 & 3.853795 & 0.000392 \\
\hline Vendors & 0.252034754 & 0.125413 & 2.009645 & 0.050922 \\
\hline Users & 0.183951772 & 0.146129 & 1.25883 & 0.215044 \\
\hline Experts & -0.091260416 & 0.136953 & -0.66636 & 0.508823 \\
\hline Demonstrations & 0.037376838 & 0.12046 & 0.310284 & 0.757879 \\
\hline Networking-Prior & 0.180124648 & 0.098837 & 1.822442 & 0.075513 \\
\hline Networking-New & -0.099834002 & 0.172562 & -0.57854 & 0.565989 \\
\hline
\end{tabular}

Figure 8: Multiple regression of informing values against the perceived overall value of JIFX

A second way to look at the question is to take a proxy for perceived value - the likelihood of returning to JIFX - and determining if a particular type or set of informing types appear to be related to that value. As noted in the literature review, the concept of fitness is closely tied to an entity's ability to survive and flourish from generation to generation. It stands to reason that for an "event entity" this would closely correlate to the likelihood that past participants would plan to attend.

Table 9: Plans to Return vs. Non-plans Experiment Value Assessments

\begin{tabular}{|c|c|c|c|c|c|c|c|c|c|}
\hline & 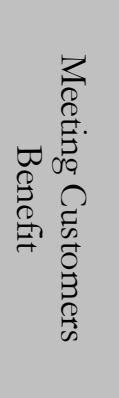 & $\begin{array}{l}3 \\
0 \\
0 \\
0 \\
5 \\
0 \\
0 \\
0 \\
0 \\
0 \\
0 \\
0 \\
0 \\
0 \\
0 \\
0 \\
0 \\
0 \\
0\end{array}$ & 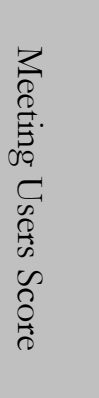 & 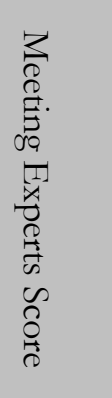 & 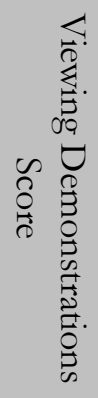 & 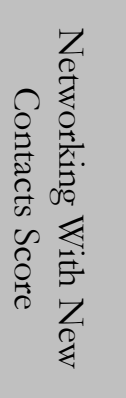 & 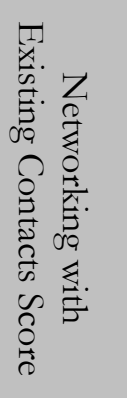 & 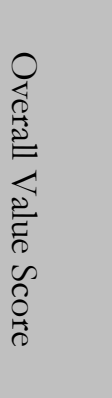 & 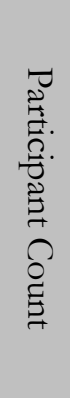 \\
\hline Plan to return & 3.23 & 3.36 & 3.82 & 3.26 & 3.03 & 4.05 & 3.44 & 4.23 & 39 \\
\hline Do not plan to return & 3.50 & 1.70 & 3.90 & 2.70 & 2.30 & 3.50 & 2.20 & 3.10 & 10 \\
\hline T-statistic & -0.63 & 3.90 & -0.19 & 1.31 & 1.71 & 1.30 & 2.91 & 2.66 & \\
\hline P-value & 0.53 & 0.00 & 0.85 & 0.20 & 0.09 & 0.20 & 0.01 & 0.01 & \\
\hline
\end{tabular}

In Table 9, reported plan to return to JIFX is compared with non-likelihood of returning for each of the informing categories as well as overall JIFX value. The strong observed relationship between overall value and expectation of returning supports the view that plans to return (a binary variable) can be treated as a reasonable proxy for perceived value. The strong significances associated with meeting vendors and networking with existing clients suggest that certain informing 
types - discovery and maintaining relationships - dominate the JIFX value proposition. This is not consistent with maximal ruggedness, wherein relatively few strong relationships would be observed. Nevertheless, it is an interesting result that confirms an important JIFX precept: that the event is not intended to be a direct source of sales (which would be indicated by high customer and user informing scores). Instead, discovery and relationship building play a particularly important role in bringing individuals back to JIFX.

\section{Discussion: JIFX as an Informing System}

The findings of our study and can be looked at from two perspectives: the individual participant and the system as a whole.

\section{Design from Experiment Participant Perspective}

From the experiment participant perspective, the informing process that occurs over the course of the JIFX event changes the shape of the informing journey fitness curve (shown earlier in Figure

2) in a number of important ways, illustrated in Figure 9.

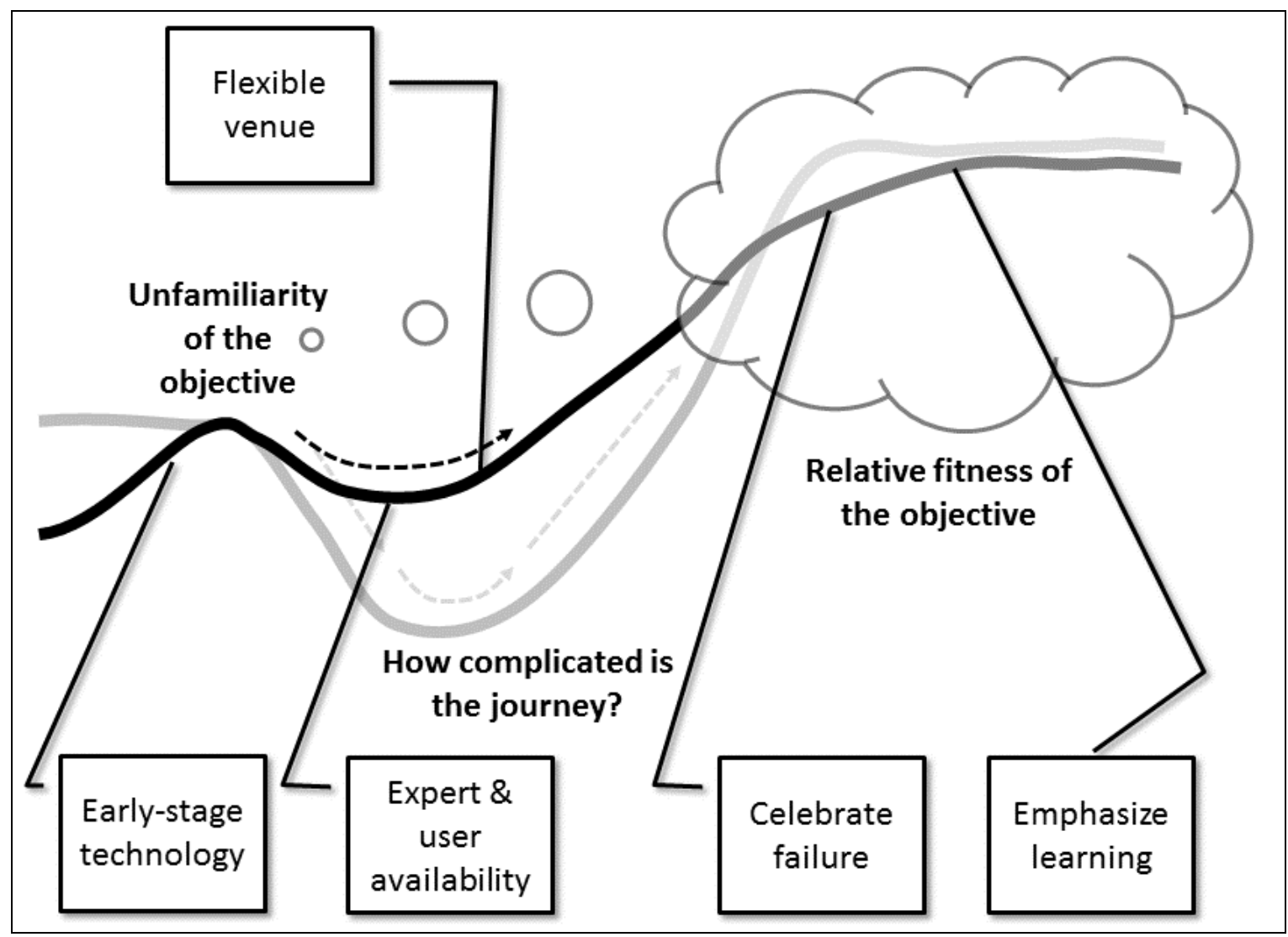

Figure 9: JIFX and the informing journey

Examples of how the JIFX event changes the curve include:

- Early stage technologies: Most of the experiments involve technologies or processes that are still under development. As a consequence, most are still climbing the fitness curve, rather than being on the fitness plateau more common to mature technologies. This reduces the amount of unfreezing required in the informing process. Example: 
Experiment 261: "We are in constant development. The most important thing we got from JIFX in terms of how we improved our software was the Joint Vulnerability Assessment branch they were able to give us some great security tips on how to improve the architecture, so we have since incorporated all of those and all of their write ups into our app...”

- Expert \& user availability: By having experts in many areas available, the loss in fitness that occurs while trying new uses, configurations, or connections is reduced. This reduces the cost of changing. Example:

Experiment 226: "We got a better sense of what the users and other participants were expecting from our product that we were developing, so we made a lot of refinements in that sense.

- Flexible venue: The JIFX event offers a flexible venue without adding the complication of a lot of existing infrastructure that requires specialized knowledge to use. This balance serves to make the complicatedness of the experiments manageable. Example:

Experiment 163: "It [JIFX] is a great test environment and opportunity to focus on field use in semi-realistic conditions. Feedback and interaction is great added bonus."

- Celebrating failure: Through its stated policy of celebrating experiments that fail for the right reasons, JIFX reduces the uncertainty associated with fitness of the end-state of the informing process as well as the fitness of the journey. Example:

Experiment 198: "We appreciate the opportunity to experiment, fail, tinker and witness collaboration toward solving real world problems. The environment fosters this and everyone is comfortable with those conditions knowing that iteration, evolution and breakthroughs can happen at JIFX rather than in a real-world situation."

- Emphasizing the learning objective of the event: JIFX explicitly eliminates "selling" as an event objective, replacing it with learning and relationship-building. This changes the nature of how fitness is judged as the event proceeds, dramatically increasing the certainty of achieving a positive outcome. Example:

Experiment 186: "Being exposed to different technology and seeing how they could work for us, but I also really appreciate the people who come and the organizations that attend. It is really nice to meet up with them in an environment that is outside of their normal because sometimes we can make a better relationship or partnership or learn more about an organization that way."

\section{System Perspective}

The other way to look at JIFX is from a full system perspective. Unfortunately, informing systems can be difficult to characterize. One approach that has been proposed (e.g., Gill, 2011) is to depict the system in terms of:

- Informing flows between entities

- Resource flows between entities

- Sensors that estimate information or resource flows

- Throttles that can increase or decrease flows 
- Control flows identifying the entities associated with the signals used to sense and control flows.

Presented in this way, based upon the observations and interviews conducted during the case research, the JIFX event can be approximately represented as shown in Figure 10.

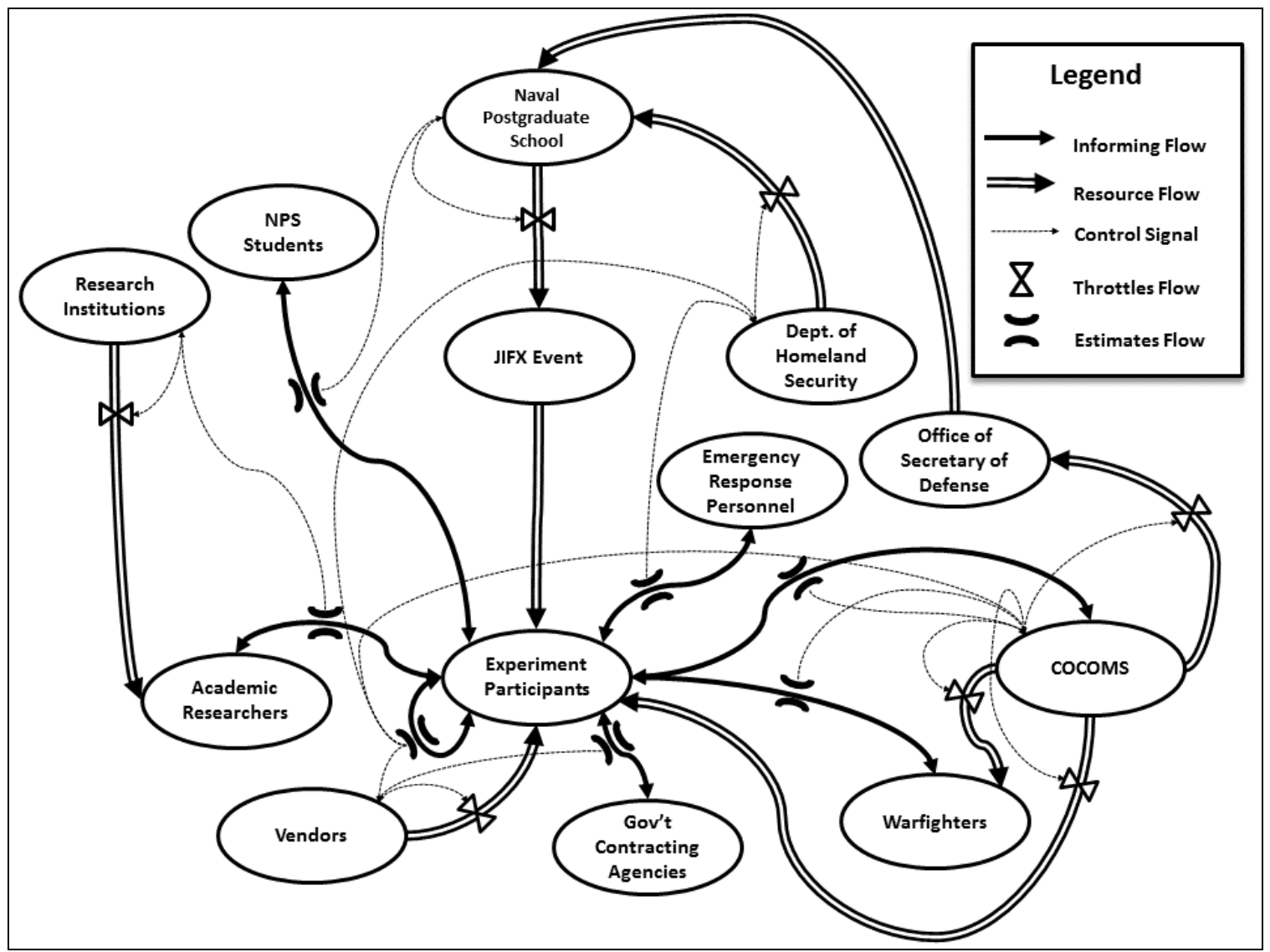

Figure 10: Informing and resource flows for the JIFX event

\section{Informing flows}

The JIFX event is built around an extraordinarily rich set of informing flows, all of which are bidirectional. The experiment participants are, of course, at the center of these flows. They interact directly with:

- Each other

- Academic researchers

- NPS student participants (who may also be experiment participants)

- Representatives of the COCOMS

- Members of the user community, such as emergency response personnel and warfighters

- Representatives of agencies that may eventually seek to purchase or acquire the product, process or system involved in the experiment

In practice, there are also potential secondary informing flows between virtually every nonexperimental participant at JIFX. These are omitted from diagram. 


\section{Resource flows}

The flow of resources that make the JIFX event possible are every bit as complicated as the informing flow. Although participants are not paid to attend JIFX, the event itself provides nonmonetary resources to participants through supplying a venue that would otherwise be costprohibitive for many of the small businesses that attend the event.

To fund the event, resources are supplied through a variety of sources. The Office of the Secretary of Defense (OSD) provides a budget for the event to the Naval Postgraduate School (NPS). While OSD does have substantial discretionary resources of its own, it requires investment by the various COCOMS (combat commands), who send their own representatives to the event. Some additional funding comes from the Department of Homeland Security.

Participants themselves must provide their own travel, shipping, and equipment. Sources of these resources can come from COCOMS (e.g., for warfighters), NPS (for its students), vendors (for private-sector participants), federal, state and local emergency management agencies (for emergency management personnel), and research institutions (for academic researchers, who may in turn be funded by grants).

\section{Control flows}

Because JIFX was specifically designed to derive its principal value from its associated informing flows, there are many explicit and implicit connections between informing flows and resource flows. We observed that nearly every resource provider was interested in the quality and quantity of informing flows between experimenters - the core objective of the event's design. This view is supported by the specific "discovery" flows detected in the factor analysis of the data. In addition, our discussions and observations made while on site suggested a strong role was played by the client-driven informing factor:

1. The COCOMS largely controlled the flow of resources both to the event (through OSD) and to the warfighters attending the event. Of particular interest to this group is the quality and quantity of informing flows between warfighters.

2. Vendors supported the attendance of experimenters (and often played dual roles) and tended to be particularly interested in the informing flows to users entities (warfighters, emergency response personnel) and to agencies that could eventually purchase or recommend purchasing their product or service.

3. Research institutions (including NPS) supported academic researchers and were particularly interested in interactions with the experimenters, who could become clients of their research (e.g., social network analysis) or sources of data.

Because many individuals had multiple roles, however, the research - particularly the qualitative findings from the interviews - suggested that the overall level of informing observed, rather than specific pathways, may have had the greatest influence on the provision of resources. This corresponded to the network-maintenance factor.

\section{Implications of flow analysis}

Central to the current research project was developing a better understanding of the nature and perceived values of the informing flows enabled by the JIFX event. The interviews and data analysis demonstrates that the associated informing flows were viewed to be highly beneficial by participants. In addition, the JIFX participants frequently referred to the uniqueness of the event. All this raises a question: does our analysis provide any insights into how the event might be improved? 
One obvious area where changes could be made would be in attempting to more accurately measure the informing patterns - informing, control, and resource flows - that, over the long run, are likely to determine the sustainability the event. Indeed, the current research was an attempt to begin looking at that these patterns.

Two major patterns seem to be of particular importance to the long term sustainability of the JIFX event. The first involves the flows of resources from the COCOMs through OSD to NPS to JIFX which, in turn, are likely to be a function of effectiveness of the various informing flows of JIFX, as discussed for Figure 9. The second involves the willingness of vendors, institutions, and agencies to continue supporting the costs of participant attendance.

An interesting question that can be raised is the degree to which more accurately quantifying the informing flows occur between various JIFX stakeholders could lead to enhanced effectiveness of the event. Favoring better measurement is a practical phenomenon: we tend to focus our activities towards improving those estimates of fitness that are most salient (Gill, 2010). Thus, we would expect the better our measurement of informing, the more of it we should get.

Weighed against this reasoning is the fact that the patterns of informing and resource flows we are considering can be characterized as cybernetic loops within the system, as illustrated in Figure 11. Resource flows are, in part, dictated by informing success; informing flows are, in turn, determined by availability of resources, and so forth.

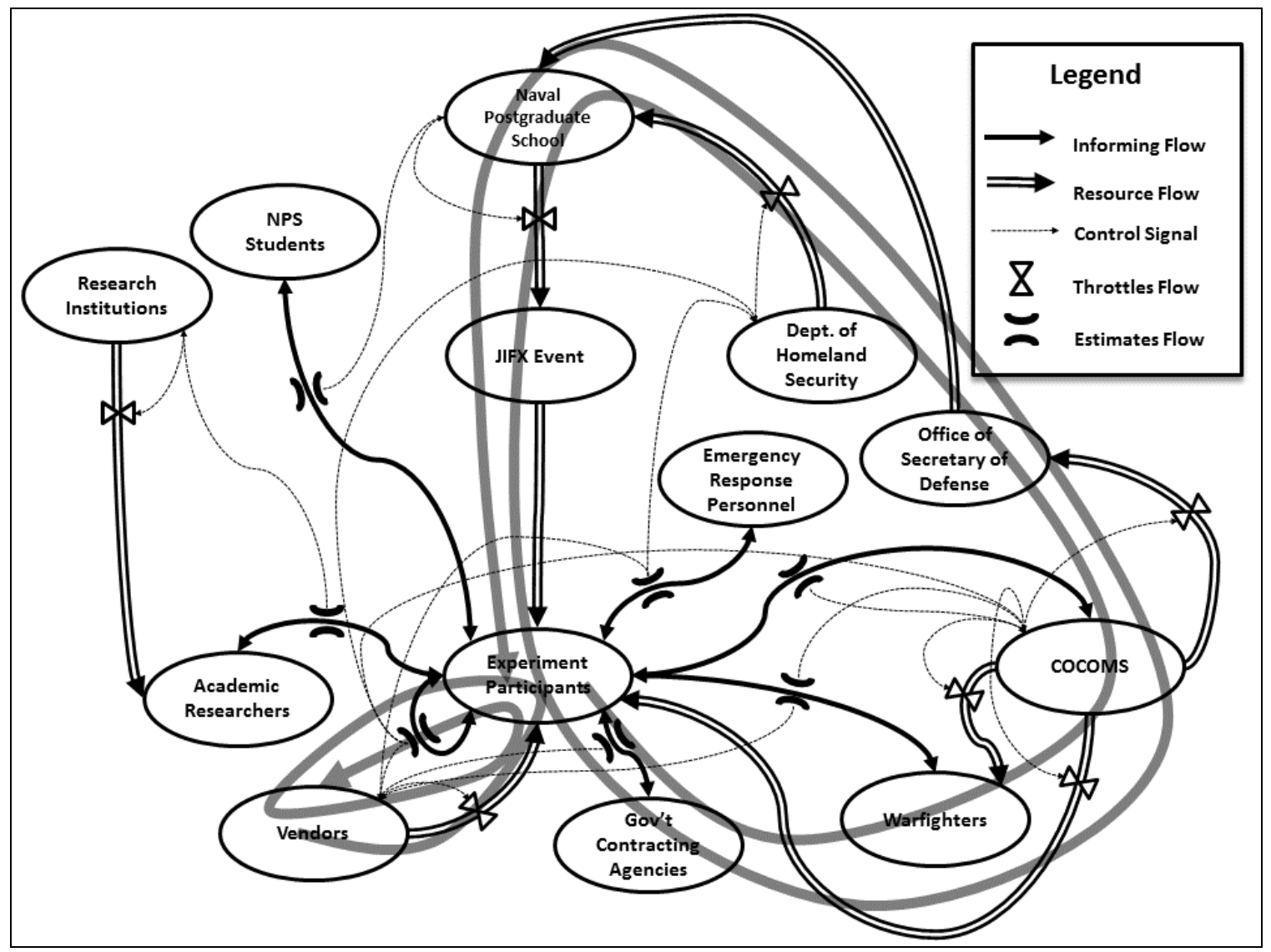

Figure 11: Major resource and informing loops of JIFX

From a pure systems theory perspective, the greater the degree these loops are governed entirely by internal signals (i.e., are isolated from outside influences), the greater the likelihood that they will start to exhibit behaviors such as exponential growth, exponential decline, cycling, or chaos 
purely as a result of systems structure. These unintended consequences could, ultimately, become so pronounced that the system as a whole could fail. To avoid such an outcome, careful thought would need to be given to the precision with which informing flows are measured and the degree to which tight coupling to resource flows is desirable. This is obviously not an issue we can resolve in this paper. It is, however, an intriguing area for future research.

\section{Conclusions}

The JIFX event was an example of an informing system designed for communication between academia, government, and industry to drive innovation. JIFX provided a unique opportunity for these parties to collaborate in an unrestricted environment. In addition, it differed from past research into situational awareness, which typically involved teams that had previously trained together (e.g., Sonnenwald \& Pierce, 2000), by virtue of the fact that the groups that participated normally emerged on an ad hoc basis.

The results of our research indicate that the principle sources of value provided by the JIFX event to its clients were from discovery, interaction with potential users of the technology, and networking. These findings are consistent with the existing literature on informing under conditions of complexity.

Beyond providing support for the existing literature, the study of the JIFX project advances the study of informing systems in a number of ways. Three of the most important are as follows.

\section{Illustrates Impact of a Rugged Fitness Function}

The fact that participants failed to identify any unique source of value from the event-and were unable to assign dollar values to their past participation - is consistent with an informing system whose fitness results from a combination of attributes, not any one attribute or set of attributes that independently produce a particular beneficial outcome. Nevertheless, the evidence is compelling that such fitness exists, with $73 \%$ of respondents indicating that the event was of considerable or great value and $80 \%$ indicating they would likely return to future events.

As evidence that value actually exists, the research found many examples of the JIFX informing system providing an opportunity for participants to refine their products to better meet user needs. This research suggests that this value was realized by both product developers and participants involved in acquisitions. It confirmed that collaboration opportunities provided by JIFX could accelerate the development process, which also benefits developers and those involved with acquisitions. It further demonstrated that multiple informing flows occur in JIFX: between product developers, between developers and experts, between developers and end-users, between developers and potential customers. Examples where these informing flows led to tangible benefits were identified. These benefits included:

- $\quad$ accelerated defect detection

- $\quad$ accelerated product improvement

- $\quad$ improved product or system design

2. Demonstrates how informing system design can promote evolutionary adaptation

In its early days (e.g., Cohen, 1999), the field of informing science was most concerned with designing information systems to accomplish routine informing tasks. Over time, the emphasis expanded to include systems that continually evolved to accommodate non-routine tasks (e.g., Gill, 2009). The JIFX event provides a particularly interesting case study of an informing system that is designed to promote non-routine informing. 
A major characteristic of JIFX was its emphasis on ad-hoc collaborations and its focus on discovery and relationship building. Added to this was a high tolerance for experimental failure and its prohibition of sales activities. Together, these design elements ensured:

- JIFX "success" was framed more in terms of learning, relationship building, and risktaking than in terms of short-term tangible metrics, such as negotiated contracts and sales.

- The portfolio of experiments at JIFX consisted mainly of artifacts and processes that were not yet frozen in terms of design, features, and protocols.

- Concerns that participation in the event would lead to adverse consequences were minimized.

Conceptually, the research showed how these design elements could be framed in terms of the following: 1) reducing the challenge on unfreezing participant artifacts/processes, 2) lowering the cost of moving between possible fitness plateaus, and 3) providing alternative, albeit less tangible, measures of fitness that minimized the consequence of risk taking. The evidence of individual successes gathered over the course of the case study suggests that this could be a powerful framework for evaluating future systems.

\section{Presents and applies a conceptual framework for informing and resource flow analysis}

If informing science is to advance as a transdiscipline, tools must be developed around its key building block: the informing system. The findings of the research suggested that a tool built around mapping informing and resource flows might provide useful insights. Most significantly, it provided a basis for speculating that examining these flows in terms of their cybernetic structure might offer useful insights into system behavior and allow system designers to avoid changes that inadvertently undermine the informing benefits observed.

Specifically, a natural area for future research might include measuring the JIFX system's informing flows more precisely. What the cybernetic analysis suggests, however, is that great care would need to be taken so that the measurement of those flows did not change the flavor and design elements of the event that seem to be providing value to the participants. The danger is that more precise - but not necessarily better - measurement of informing could lead to tighter coupling between resource flows and certain specific informing flows. That coupling could lead to a profound effect on the dynamics of the event and could, in fact, reduce its overall ability to support complex informing.

In conclusion, the JIFX event provided a unique opportunity to conduct a field study of a remarkable informing system and consider its design and impact from multiple perspectives. Such research necessarily diverges from narrowly focused hypothesis testing; the scope of the event and its stakeholders was simply too broad. Fortunately, the transdisciplinary philosophy of informing science provides us with a toolkit drawn from many disciplines that we can apply to investigations such as these. In doing so, however, we continually find ourselves needing to further refine the tools that we have available and to develop new ones. In other words, it is through systematic observation and analysis of sites such as the JIFX event that informing science can continue to evolve.

\section{References}

Bordetsky, A., \& Netzer, D. (2010). Testbed for tactical networking and collaboration. The International C2 Journal, 4(3). Retrieved from http://www.dodccrp.org/files/IC2J_v4n3_B Bordetsky.pdf 
Buettner, R.R., Jr. (2013). Multi-institutional semi-structured learning environments, Journal of Systems, Cybernetics and Informatics, 11(7), 50-53. Retrieved from: http://www.iiisci.org/journal/sci/FullText.asp?var=\&id=iIR383XN

Campbell, D. J. (1988). Task complexity: A review and analysis. Academy of Management Review, 13(1), $40-52$.

Cohen, E. (1999). Reconceptualizing information systems as a field of the transdiscipline informing science: From ugly duckling to swan. Journal of Computing and Information Technology, 7(3), 213-219.

Gill, T. G. (2009). Chapter 22: Routine versus non-routine informing: Reflections on what I have learned. In T. G. Gill \& E. B. Cohen (Eds.). (2009). Foundations of informing science: 1999-2008. Santa Rosa, CA: Informing Science Press.

Gill, T. G. (2010). Informing business: Research and education on a rugged landscape. Santa Rosa, CA: Informing Science Press.

Gill, T. G. (2011). Informing with the case method. Santa Rosa, CA: Informing Science Press.

Gill, T. G. (2012). Informing on a rugged landscape: Homophily versus expertise. Informing Science: the International Journal of an Emerging Transdiscipline, 15, 49-91. Retrieved from http://www.inform.nu/Articles/Vol15/ISJv15p049-091Gill616.pdf

Gill, T.G., \& Hevner, A. (2011). A fitness-utility model for design science research. Proceedings of the Design Science Research in Information Systems and Technology (DESRIST 2011), Milwaukee, WI.

Gill, T. G., \& Hicks, R. (2006). Task complexity and informing science: A synthesis. Informing Science: The International Journal of an Emerging Transdiscipline, 9, 1-30. Retrieved from http://www.inform.nu/Articles/Vol9/v9p001-030Gill46.pdf

Gill, T. G., \& Jones, J. (2010). A tale of three classes: Case studies in course complexity. Journal of Information Technology Education, 9, 1-29. Retrieved from http://www.jite.org/documents/Vol9/JITEv9p001-029Gill717.pdf

Gill, T. G., \& Murphy, W. (2011). Task complexity and design science. 9th International Conference on Education and Information Systems, Technologies and Applications (EISTA 2011), Orlando, FL.

Hevner, A. R., Davis, C., Collins, R. W., \& Gill, T. G. (2014). A neurodesign model for IS research. Informing Science: the International Journal of an Emerging Transdiscipline, 17, 103-132. Retrieved from http://www.inform.nu/Articles/Vol17/ISJv17p103-132Hevner.pdf

Kauffman, S.A. (1993). The origins of order. Oxford, UK: Oxford University Press.

Keller, L.R., Simon, J., \& Wang, Y. (2009). Multiple-objective decision analysis involving multiple stakeholders. Inform Tutorials in Operations Research. doi: 10.1287/educ.1090.0066

Lewin, K. (1989). Changing as three steps: Unfreezing, moving, and freezing of group standards. Organizational Development: Theory, Practice, and Research, 87.

Manuel, C. E., Murphy Jr., H. R., \& Paxton, K. A. (2004). The surveillance and target acquisition network $(S T A N)$. (Master's thesis, Naval Postgraduate School). Access restricted.

Oros, C. (2014). A brief history of the NPS field experimentation program spanning STAN, TNT and JIFX, Naval Postgraduate School Technical Report, NPS-F X-14-003

Sonnenwald, D. H. \& Pierce, L. G. (2000). Information behavior in dynamic group work contexts: Interwoven situational awareness, dense social networks and contested collaboration in command and control. Information Processing and Management, 36(3), 461-479.

Wessa, P. (2014). Free statistics software. Office for Research Development and Education, version 1.1.23-r7. Available at http://www.wessa.net/

Wood, R. (1986). Task complexity: Definition of the construct. Organizational Behavior and Human Decision Processes, 37, 60-82. 


\section{Acknowledgments}

Support for the research presented in this paper was provided by the U.S. Office of Naval Research, Contract Number N00244-13-1-0049. All views expressed in this paper are the responsibility of the authors.

\section{Biographies}

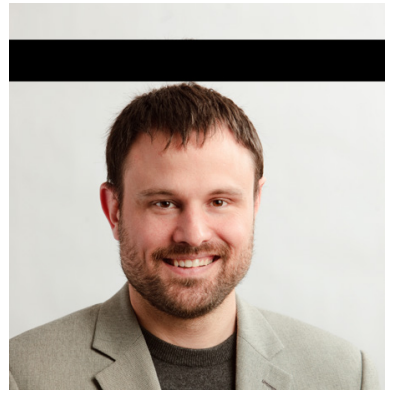

William F. Murphy, Jr., has nearly 20 years of industry experience. Dr. Murphy has held Chief Information Officer Positions at several firms. He has a Masters of Arts in Applied Economics from the University of Central Florida, a Master's of Science in Risk Management Finance from Florida State University, and a Ph.D. in Information Systems and Decision Sciences from the University of South Florida. His personal consultancy researches and develops mobile applications for large companies, and provides confidential merger and acquisition diligence services for intellectual property related acquisitions.

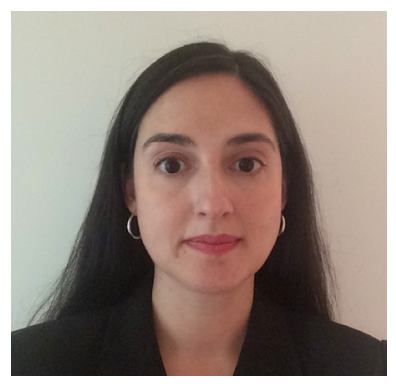

Sandra S. Murphy is a graduate student working on her Ph.D. in Curriculum \& Instruction with a Concentration in Instructional Technology at the University of South Florida, and holds a Masters of Arts in Elementary Education also from the University of South Florida. Her personal consultancy researches and develops mobile applications for large companies, and provides confidential merger and acquisition diligence services for intellectual property related acquisitions. Her experience includes usability testing and mobile application, web, and ebook solutions for education and training.

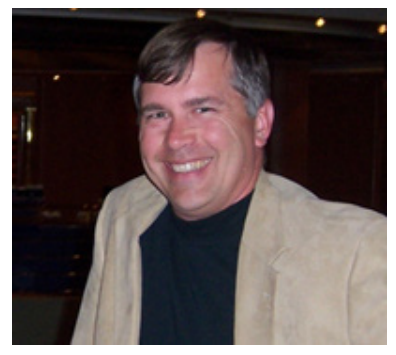

Ray Buettner is an Associate Professor of Information Sciences at the Naval Postgraduate School in Monterey, California where he is the Joint Staff Chair of Technical Operations. His primary teaching is in the areas of systems engineering, cyber operations and information warfare. He is the Principle Investigator for two major research programs with more than $\$ 5$ million in funding. His primary research areas are related to collaborative learning environments and robotic/unmanned systems.

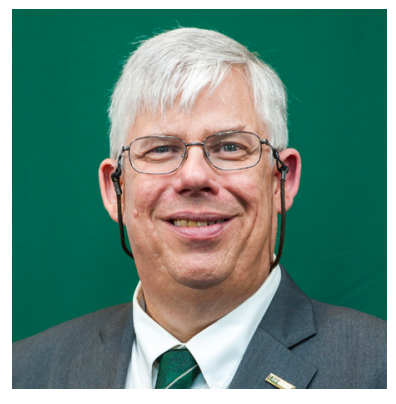

Grandon Gill is a professor in the Information Systems and Decision Sciences department of the University of South Florida. He is also the Academic Director of the Doctor of Business Administration program at the Muma College of Business. He is Editor-in-Chief of Informing Science: The International Journal of an Emerging Transdiscipline and the Journal of IT Education: Discussion Cases, also serving as a Governor and Fellow of the Informing Science Institute. In 2014, he was the inaugural recipient of the Zbigniew Gackowski Award for contributions to informing science research. 


\section{Appendix A: Online Survey Form}

Respondent Information
The purpose of this survey is to make the phone interviews that are the heart of this study more efficient (thereby taking as little of your time as
possible). You may skip any questions you choose to, since we will pick them up when we contact you-the one exceptions being your
experiment identifier (contained in the email we sent you), since that is the only way we have of matching the survey responses to the
experiment. If you strongly prefer that we do not contact you by phone, you may specify this on this page.
1. JifX Experiment Identifier*
The code provided in the email that we sent you, created so that we may link survey responses to the project
2. Your last name
Your first name (or preferred name)
3.

\section{Organization Information}

This page requests information relating to the organization that participated in the JIFX event.

4. Is your organization a small business, under 50 employees?

No $\quad \checkmark$

5. Is your organization a private non-profit?

No $\quad \checkmark$

6. Is your organization a public non-military agency?

No $\quad \checkmark$

7. Is your organization part of the military?

No $\quad \checkmark$

8. Is your organization a defense contractor?

No $\quad \checkmark$

Back Next Save Cancel




\section{JIFX Participant}

Page 3 of 6

\section{Experiment Information}

This page requests information relating to the experiments conducted during the specified JIFX event.

9. Did the experiment proposal include a test of equipment?

$$
\text { No } \quad \checkmark
$$

10. Did the experiment proposal include a test of software?

$$
\text { No }
$$

$$
\checkmark
$$

11. Did the experiment proposal include a test of a new process or procedure?

$$
\text { No }
$$

$$
\checkmark
$$

12. Did the experiment proposal involve connecting components into a system?

$$
\text { No } \vee
$$

13. Was the experiment proposal IT related?

$$
\text { No }
$$

14. Did the experiment proposal include a planned collaboration with other participants outside your organization? No

15. Did the actual experiment include unplanned (ad hoc) collaboration with other participants outside your organization? (No if not applicable)
No

16. Did the experiment proposal involve an existing product or service available commercially?

$$
\text { No }
$$

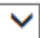

17. Did the experiment proposal involve a prototype or incomplete product not yet available commercially?

$$
\text { No }
$$

18. Did the experiment proposal involve a product or service likely to be broadly applicable to warfare? No

19. Did the experiment proposal involve a product or service likely to be broadly applicable to disaster relief?

$$
\text { No }
$$




\section{JIFX Participant}

\section{Outcome Information}

An important element of the survey is assessing the impact, if any, on products or services that were tested or demonstrated at JIFX

20. Was the product, service or process demonstrated at JIFX for sale at the time (No if not applicable)?

No $v$

21. Is the product, service or process demonstrated at JIFX currently for sale or intended for future sale (No if not applicable)?

No $\quad \checkmark$

22. Has further development on the product, service or process demonstrated at JIFX been abandoned (No if not applicable)?

No $\checkmark$

23. Does your organization have any estimate of the net financial impact (benefits-costs) of the JIFX experiment?

No $\checkmark$

24. If the answer to the previous question was YES, what was the net value estimated?Positive number in $\$$ (or negative value if costs were larger than estimated benefits)

larger than estimated

25. If you were able to supply a value for the previous question, can you briefly describe how it was arrived at?

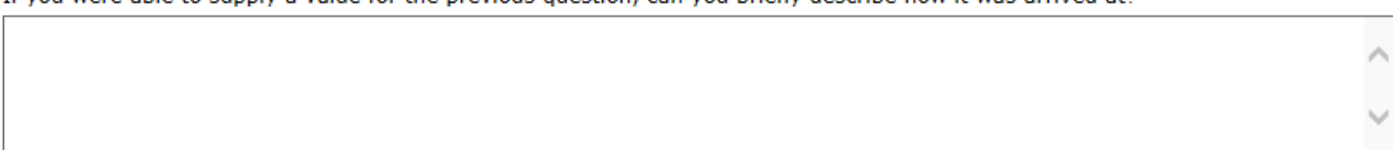

26. Please identify the sources of any value that may have resulted from participating in JIFX

\begin{tabular}{|c|c|c|c|c|c|c|}
\hline & No value & $\begin{array}{l}\text { Little } \\
\text { value }\end{array}$ & $\begin{array}{l}\text { Some } \\
\text { value }\end{array}$ & $\begin{array}{l}\text { Significant } \\
\text { value }\end{array}$ & $\begin{array}{l}\text { Great } \\
\text { value }\end{array}$ & $\begin{array}{l}\text { Not } \\
\text { applicable }\end{array}$ \\
\hline Meeting potential customers & $\mathrm{O}$ & 0 & 0 & 0 & 0 & O \\
\hline $\begin{array}{l}\text { Meeting potential vendors of other products or } \\
\text { services }\end{array}$ & $\mathrm{O}$ & $\mathrm{O}$ & $\mathrm{O}$ & $\mathrm{O}$ & $\mathrm{O}$ & $\mathrm{O}$ \\
\hline Meeting potential users of the product or service & $\bigcirc$ & $\bigcirc$ & $\bigcirc$ & O & O & $\bigcirc$ \\
\hline Meeting experts in the area & $\mathrm{O}$ & $\mathrm{O}$ & $\mathrm{O}$ & $\mathrm{O}$ & $\mathrm{O}$ & $\mathrm{O}$ \\
\hline $\begin{array}{l}\text { Viewing demonstrations of related products, } \\
\text { processes or services }\end{array}$ & $\mathrm{O}$ & $\mathrm{O}$ & $\bigcirc$ & $\bigcirc$ & 0 & $\mathrm{O}$ \\
\hline $\begin{array}{l}\text { Networking with individuals I/we had never met } \\
\text { before }\end{array}$ & $\mathrm{O}$ & $\mathrm{O}$ & $\mathrm{O}$ & $\mathrm{O}$ & $\mathrm{O}$ & $\mathrm{O}$ \\
\hline Networking with prior contacts & 0 & 0 & 0 & $\mathrm{O}$ & 0 & $\mathrm{O}$ \\
\hline
\end{tabular}

27. Did you follow-up with any individuals you met at JIFX?
No
$\checkmark$

28. If the answer to the previous question was yes, can you briefly describe the nature of the follow-up?

Back Next Save Cancel




\section{JIFX Participant}

Future of JIFX

This page, which completes the survey, is intended to assess your future JIFX plans and get your overall assessment of the exercise (in case you attended more than one).

29. Does your organization have any plans to attend a future JIFX event? No

30. Can you explain why or why not?

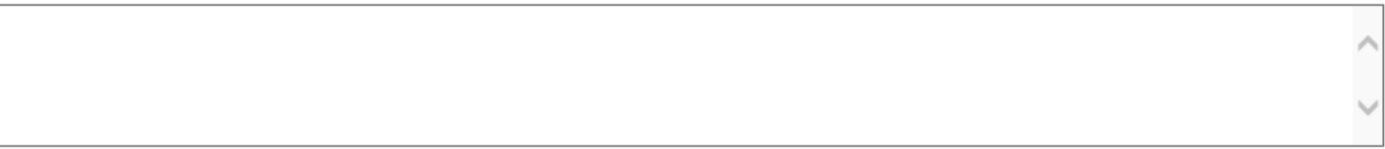

31. What is you overall assessment of JIFX as an event (not necessarily just the experiment described in this survey)
No value
Little value
Some value
Significant value
Extremely valuable
Don't have an opinion

32. What do you see as the most significant sources of value from JIFX events?

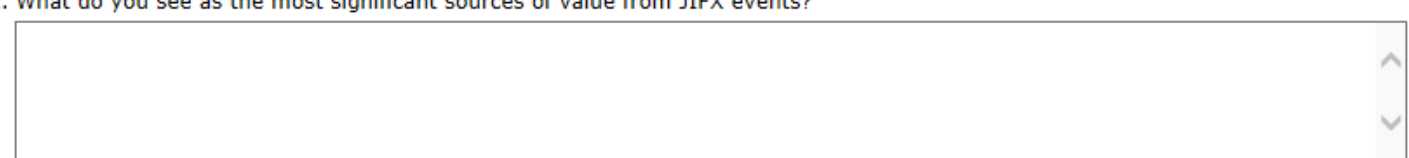

33. Do you have any suggestions for improving future JIFX events?

Back Next Save Cancel




\section{JIFX Participant}

Page 6 of 6

\section{Follow Up}

Information related to the follow-up phone call that is part of the protocol

34. I have completed all relevant items in the survey Completing all items is not required. Knowing you have done so will likely make any subsequent phone interview shorter. No

35. Best email address for contacting you

36. Your preferred phone number

37. Follow up interview

The study protocol specifies that we contact each respondent by phone. You may decline to participate further below.

- You may contact me by email to set up a convenient time for a phone interview

I have completed the form, and prefer not to be contacted further

I have partially completed the form, and prefer not to be contacted further

I decline to participate further in this survey 


\section{Appendix B: Profile of Interview Responses}

\begin{tabular}{|c|c|c|}
\hline Question & Percent True & Percent False \\
\hline Is your organization a startup? & $21 \%$ & $79 \%$ \\
\hline Is your organization a small business, under 50 employees? & $50 \%$ & $50 \%$ \\
\hline Is your organization a private non-profit? & $12 \%$ & $88 \%$ \\
\hline Is your organization a non-military governmental agency? & $10 \%$ & $90 \%$ \\
\hline Is your organization part of the military? & $21 \%$ & $79 \%$ \\
\hline Is your organization a defense contractor? & $41 \%$ & $59 \%$ \\
\hline Did the experiment proposal include a test of software? & $69 \%$ & $31 \%$ \\
\hline $\begin{array}{l}\text { Did the experiment proposal include a test of a new process or } \\
\text { procedure? }\end{array}$ & $54 \%$ & $46 \%$ \\
\hline $\begin{array}{l}\text { Did the experiment proposal involve connecting components } \\
\text { into a system? }\end{array}$ & $67 \%$ & $33 \%$ \\
\hline Was the experiment proposal IT related? & $60 \%$ & $40 \%$ \\
\hline $\begin{array}{l}\text { Did the experiment proposal include a planned collaboration } \\
\text { with other participants? }\end{array}$ & $50 \%$ & $50 \%$ \\
\hline $\begin{array}{l}\text { Did the experiment proposal involve an existing product or ser- } \\
\text { vice available commercially? }\end{array}$ & $48 \%$ & $52 \%$ \\
\hline $\begin{array}{l}\text { Did the experiment proposal involve a prototype or incomplete } \\
\text { product not yet available commercially? }\end{array}$ & $60 \%$ & $40 \%$ \\
\hline $\begin{array}{l}\text { Did the experiment proposal involve a product or service likely } \\
\text { to be broadly applicable to warfare? }\end{array}$ & $82 \%$ & $18 \%$ \\
\hline $\begin{array}{l}\text { Did the experiment proposal involve a product or service likely } \\
\text { to be broadly applicable to disaster relief? }\end{array}$ & $88 \%$ & $12 \%$ \\
\hline $\begin{array}{l}\text { Was the product, service or process demonstrated at JIFX for } \\
\text { sale at the time (No if not applicable)? }\end{array}$ & $33 \%$ & $67 \%$ \\
\hline $\begin{array}{l}\text { Is the product, service or process demonstrated at JIFX currently } \\
\text { for sale or intended for future sale (No if not applicable)? }\end{array}$ & $78 \%$ & $22 \%$ \\
\hline $\begin{array}{l}\text { Has further development on the product, service or process } \\
\text { demonstrated at JIFX been abandoned (No if not applicable)? }\end{array}$ & $2 \%$ & $98 \%$ \\
\hline Did you engage in any ad hoc experiments? & $69 \%$ & $31 \%$ \\
\hline
\end{tabular}




\begin{tabular}{|l|c|c|}
\hline Question & Percent True & Percent False \\
\hline Was the impact positive? & $48 \%$ & $52 \%$ \\
\hline Did JIFX impact the design of the (product, process, service)? & $23 \%$ & $77 \%$ \\
\hline $\begin{array}{l}\text { Was the impact of JIFX impact on the (product, process, ser- } \\
\text { vice) unexpected? }\end{array}$ & $6 \%$ & $94 \%$ \\
\hline Is there a financial value estimated for the impact? & $16 \%$ & $84 \%$ \\
\hline Did you follow-up with any individuals you met at JIFX? & $88 \%$ & $12 \%$ \\
\hline
\end{tabular}




\section{Appendix C: Perceived Value by Participant and Experiment Type Results}

\section{Participant Analysis}

To assess whether substantial differences in perceived informing patterns between different types of participant organizations existed, a simple T-test to compare the means value between participants of a particular type and the remainder of the sample was conducted.

\section{Startup Participants}

The perceived values of startup participants are presented in Table C.1. Startups appeared to realize particularly high relative benefit gains from meeting vendors.

Table C.1: Startup and Other Participant Value Assessments

\begin{tabular}{|c|c|c|c|c|c|c|c|c|c|}
\hline & 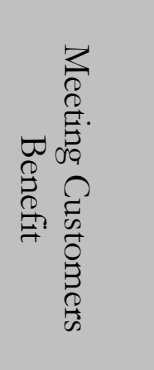 & 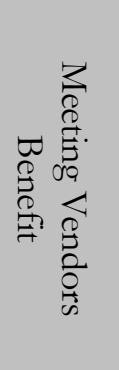 & 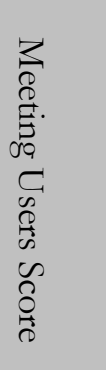 & 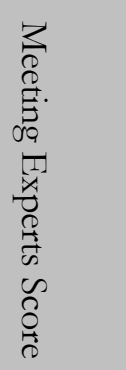 & 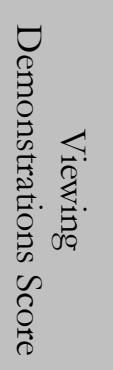 & 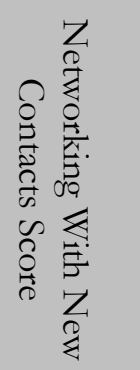 & 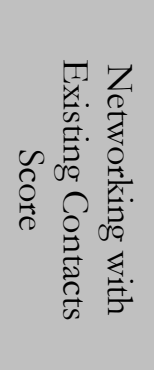 & 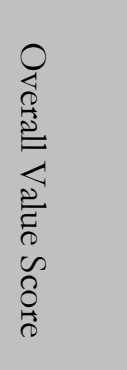 & 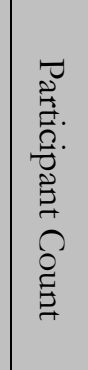 \\
\hline Startups & 3.90 & 3.90 & 3.80 & 3.40 & 3.00 & 3.70 & 3.50 & 4.00 & 10 \\
\hline Other participants & 3.13 & 2.79 & 3.85 & 3.08 & 2.85 & 4.00 & 3.10 & 4.00 & 39 \\
\hline T-statistic & 1.81 & 2.60 & -0.11 & 0.76 & 0.36 & -0.71 & 0.93 & 0 & \\
\hline $\mathrm{P}$-value & 0.08 & 0.01 & 0.91 & 0.45 & 0.72 & 0.48 & 0.35 & 1 & \\
\hline
\end{tabular}

\section{Small Business Participants}

The perceived values of small business participants are presented in Table C.2. No significant differences were identified between small businesses and other participants.

Table C.2: Small Business and Other Participant Value Assessments

\begin{tabular}{|c|c|c|c|c|c|c|c|c|c|}
\hline & 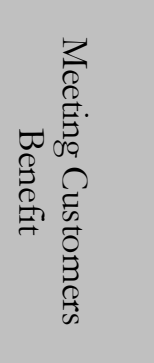 & 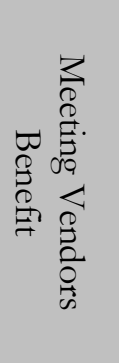 & 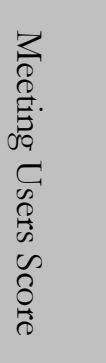 & 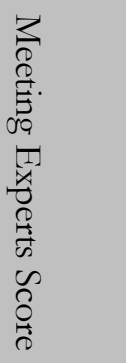 & 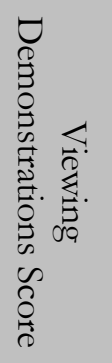 & 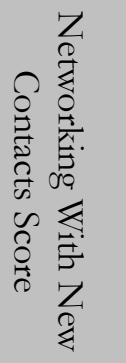 & 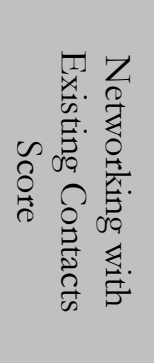 & 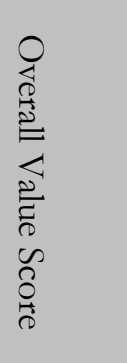 & 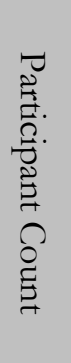 \\
\hline Small Businesses & 3.33 & 3.29 & 4.13 & 3.25 & 3.00 & 4.13 & 3.29 & 4.17 & 24 \\
\hline Other participants & 3.24 & 2.76 & 3.56 & 3.04 & 2.76 & 3.76 & 3.08 & 3.84 & 25 \\
\hline T-statistic & 0.27 & 1.55 & 1.65 & 0.61 & 0.70 & 1.06 & 0.62 & 0.95 & \\
\hline $\mathrm{P}$-value & 0.79 & 0.13 & 0.11 & 0.54 & 0.49 & 0.29 & 0.54 & 0.35 & \\
\hline
\end{tabular}




\section{Non-Profit Participants}

The perceived values of non-profit participants are presented in Table C.3. No significant differences were identified between non-profit and other participants. Given the small number of nonprofits in the sample, such lack of significance is not surprising. Some fairly large differences in average responses were observed, however, particular for meeting vendors (less valued by nonprofits) as well as viewing demonstrations and networking with existing contacts (more valued by non-profits).

Table C.3: Non-Profit and Other Participant Value Assessments

\begin{tabular}{|c|c|c|c|c|c|c|c|c|c|}
\hline & 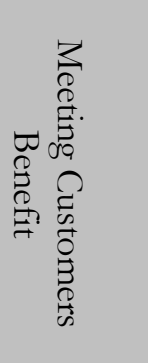 & 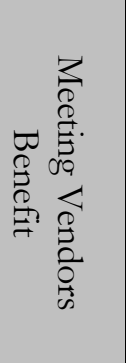 & 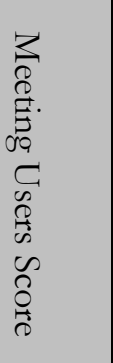 & 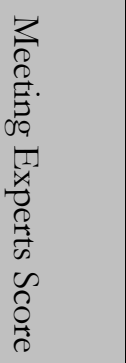 & 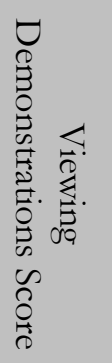 & 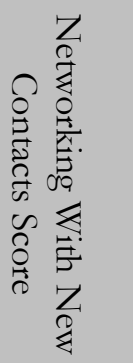 & 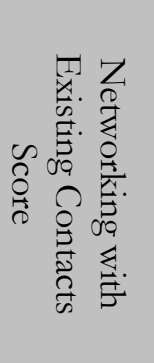 & 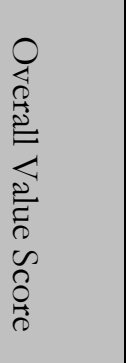 & 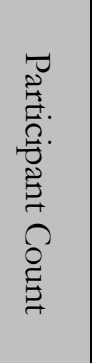 \\
\hline Non-profits & 2.67 & 2.17 & 3.50 & 3.67 & 3.67 & 4.00 & 4.00 & 4.00 & 6 \\
\hline Other participants & 3.37 & 3.14 & 3.88 & 3.07 & 2.77 & 3.93 & 3.07 & 4.00 & 43 \\
\hline T-statistic & -1.35 & -1.86 & -0.73 & 1.14 & 1.72 & 0.13 & 1.78 & 0.00 & \\
\hline P-value & 0.18 & 0.07 & 0.47 & 0.26 & 0.09 & 0.89 & 0.08 & 1.00 & \\
\hline
\end{tabular}

\section{Government Agency Participants}

The perceived values of government agency participants are presented in Table C.4. No significant differences were identified between government agency and other participants. Given the small number of government agencies in the sample, such lack of significance is not surprising.

Table C.4: Government Agency and Other Participant Value Assessments

\begin{tabular}{|c|c|c|c|c|c|c|c|c|c|}
\hline & 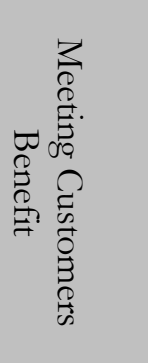 & 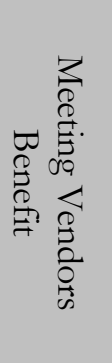 & 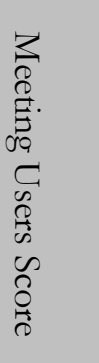 & 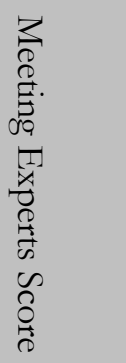 & 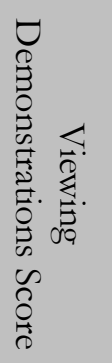 & 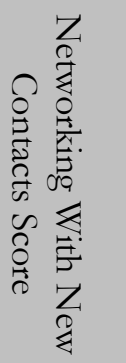 & 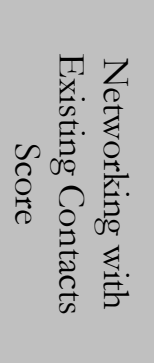 & 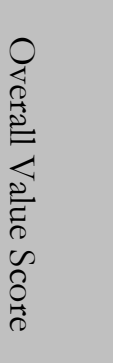 & 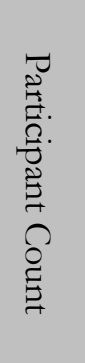 \\
\hline Gov't Agencies & 3.00 & 2.20 & 3.60 & 2.40 & 2.20 & 3.00 & 3.20 & 4.00 & 5 \\
\hline Other participants & 3.32 & 3.11 & 3.86 & 3.23 & 2.95 & 4.05 & 3.18 & 4.00 & 44 \\
\hline T-statistic & -0.56 & -1.61 & -0.47 & -1.46 & -1.33 & -1.85 & 0.03 & 0.00 & \\
\hline P-value & 0.58 & 0.11 & 0.64 & 0.15 & 0.19 & 0.07 & 0.97 & 1.00 & \\
\hline
\end{tabular}




\section{Military Participants}

The perceived values of military participants are presented in Table C.5. No significant differences were identified between government agency and other participants.

Table C.5: Military and Other Participant Value Assessments

\begin{tabular}{|c|c|c|c|c|c|c|c|c|c|}
\hline & 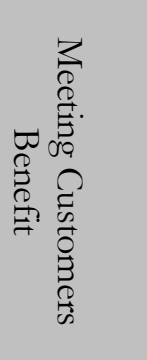 & 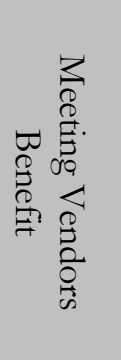 & 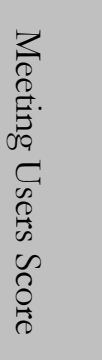 & 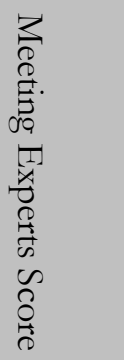 & 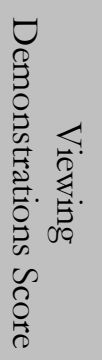 & 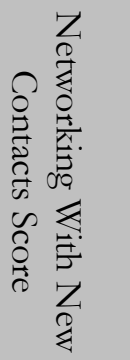 & 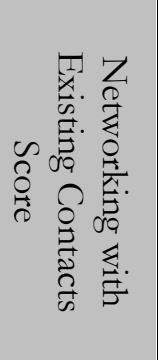 & 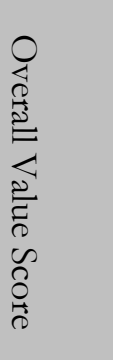 & 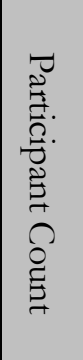 \\
\hline Military & 3.20 & 2.80 & 3.50 & 2.90 & 3.00 & 3.70 & 3.40 & 4.00 & 10 \\
\hline Other participants & 3.31 & 3.08 & 3.92 & 3.21 & 2.85 & 4.00 & 3.13 & 4.00 & 39 \\
\hline T-statistic & -0.25 & -0.65 & -0.99 & -0.72 & 0.36 & -0.71 & 0.64 & 0.00 & \\
\hline $\mathrm{P}$-value & 0.80 & 0.52 & 0.32 & 0.48 & 0.72 & 0.48 & 0.53 & 1.00 & \\
\hline
\end{tabular}

\section{Defense Contractors}

The perceived values of defense contractor participants are presented in Table C.6. Defense contractors appeared to realize particularly high relative benefit gains from viewing demonstrations.

Table C.6: Defense Contractor and Other Participant Value Assessments

\begin{tabular}{|c|c|c|c|c|c|c|c|c|c|}
\hline & 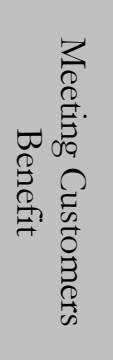 & 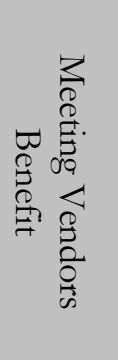 & 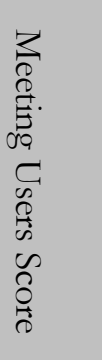 & 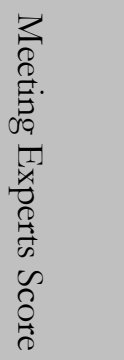 & 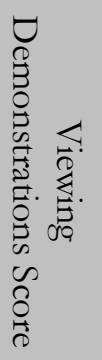 & 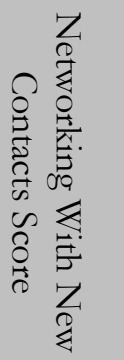 & 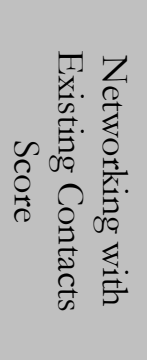 & 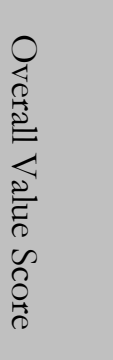 & 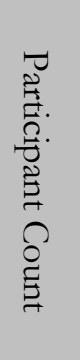 \\
\hline Defense contractors & 3.65 & 3.20 & 4.05 & 2.85 & 2.40 & 3.90 & 2.90 & 3.80 & 20 \\
\hline Other participants & 3.03 & 2.90 & 3.69 & 3.34 & 3.21 & 3.97 & 3.38 & 4.14 & 29 \\
\hline T-statistic & 1.76 & 0.87 & 1.03 & -1.42 & -2.31 & -0.19 & -1.37 & -0.97 & \\
\hline P-value & 0.08 & 0.39 & 0.31 & 0.16 & 0.03 & 0.85 & 0.18 & 0.34 & \\
\hline
\end{tabular}




\section{Informing Value by Experiment Type}

To assess whether substantial differences in perceived informing patterns between different types of experiments existed, a simple T-test to compare the means value between experiments of a particular type and the remainder of the sample was conducted.

\section{Equipment Experiments}

The perceived values of equipment experiments are presented in Table C.7. Experiments involving equipment appeared to derive greater benefits from meeting other vendors and reduced benefits from meeting experts.

Table C.7: Equipment Experiments and Other Experiment Value Assessments

\begin{tabular}{|c|c|c|c|c|c|c|c|c|c|}
\hline & 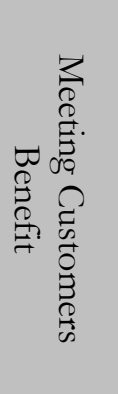 & 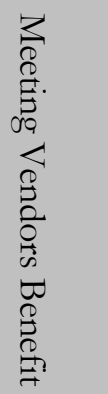 & 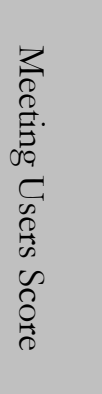 & 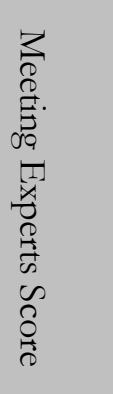 & 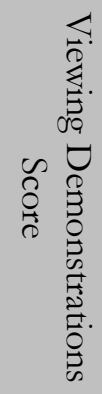 & 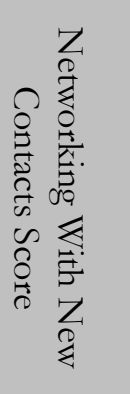 & 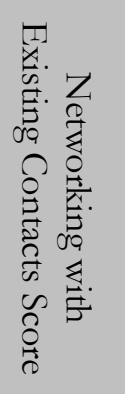 & 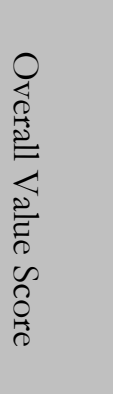 & 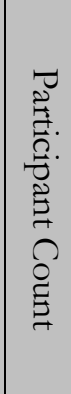 \\
\hline Equipment experiments & 3.40 & 3.23 & 3.93 & 2.98 & 2.73 & 3.88 & 3.15 & 4.15 & 40 \\
\hline Other experiments & 2.78 & 2.11 & 3.44 & 3.89 & 3.56 & 4.22 & 3.33 & 3.33 & 9 \\
\hline T-statistic & 1.41 & 2.52 & 1.09 & -2.06 & -1.88 & -0.78 & -0.41 & 1.84 & \\
\hline $\mathrm{P}$-value & 0.17 & 0.02 & 0.28 & 0.04 & 0.07 & 0.44 & 0.68 & 0.07 & \\
\hline
\end{tabular}

\section{Software Experiments}

The perceived values of equipment experiments are presented in Table C.8. Experiments involving equipment appeared to derive greater benefits from viewing demonstrations.

Table C.8: Software Experiments and Other Experiment Value Assessments

\begin{tabular}{|c|c|c|c|c|c|c|c|c|c|}
\hline & 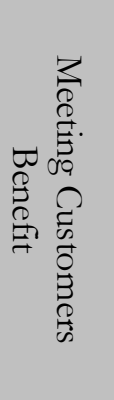 & 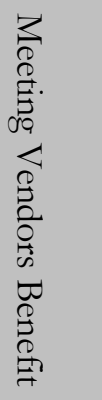 & 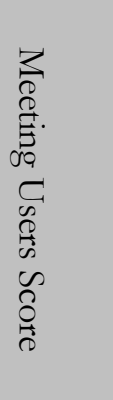 & 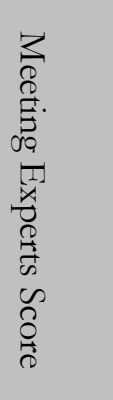 & 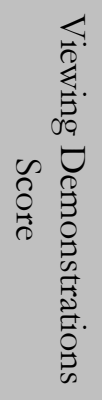 & 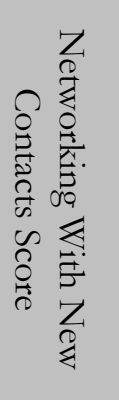 & 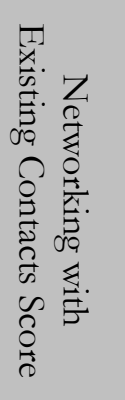 & 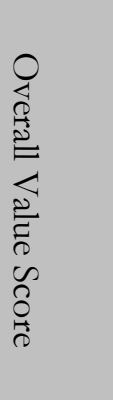 & 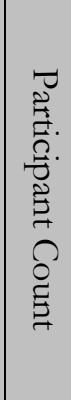 \\
\hline Software experiments & 3.12 & 3.00 & 3.73 & 3.12 & 2.64 & 4.00 & 3.18 & 3.97 & 33 \\
\hline Other experiments & 3.63 & 3.06 & 4.06 & 3.19 & 3.38 & 3.81 & 3.19 & 4.06 & 16 \\
\hline T-statistic & -1.38 & -0.17 & -0.92 & -0.18 & -2.02 & 0.51 & -0.02 & -0.25 & \\
\hline P-value & 0.17 & 0.86 & 0.36 & 0.86 & 0.05 & 0.61 & 0.99 & 0.80 & \\
\hline
\end{tabular}




\section{Process Experiments}

The perceived values of experiments involving a test of a process are presented in Table C.9. Experiments involving process tests appeared to derive greater overall value from JIFX informing than other experiments. Indeed, the only category where they scored lower than non-process experiments was in meeting other customers.

Table C.9: Process Experiments and Other Experiment Value Assessments

\begin{tabular}{|c|c|c|c|c|c|c|c|c|c|}
\hline & 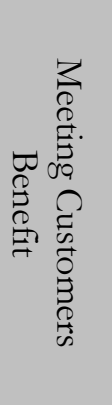 & 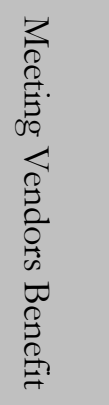 & 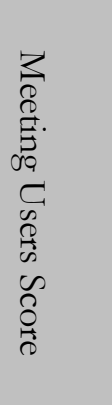 & $\begin{array}{l}3 \\
2 \\
0 \\
0 \\
5 \\
09 \\
0 \\
01 \\
0 \\
0 \\
0 \\
0 \\
0 \\
0 \\
0 \\
0 \\
0 \\
0\end{array}$ & 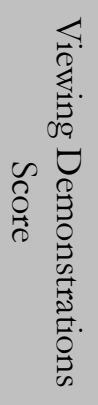 & 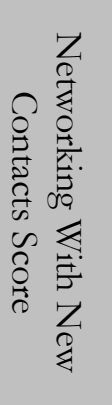 & 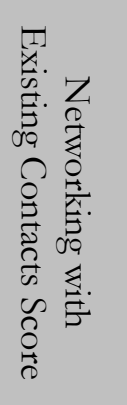 & 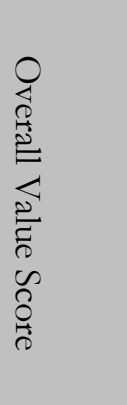 & 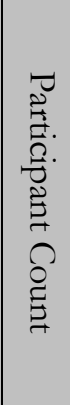 \\
\hline Process experiments & 3.15 & 3.23 & 3.85 & 3.23 & 3.19 & 3.96 & 3.50 & 4.35 & 26 \\
\hline Other experiments & 3.43 & 2.78 & 3.83 & 3.04 & 2.52 & 3.91 & 2.83 & 3.61 & 23 \\
\hline T-statistic & -0.82 & 1.30 & 0.06 & 0.55 & 1.95 & 0.14 & 1.96 & 2.15 & \\
\hline P-value & 0.42 & 0.20 & 0.95 & 0.59 & 0.06 & 0.89 & 0.06 & 0.04 & \\
\hline
\end{tabular}

\section{System Experiments}

The perceived values of experiments involving an integrated system are presented in Table C.10. Experiments involving systems did not appear to differ significantly from other experiments.

Table C.10: System Experiments and Other Experiment Value Assessments

\begin{tabular}{|c|c|c|c|c|c|c|c|c|c|}
\hline & 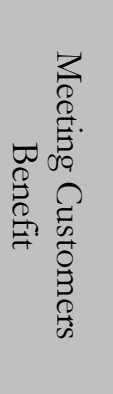 & 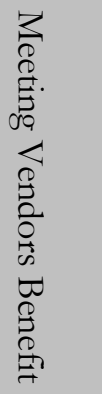 & 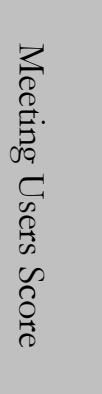 & 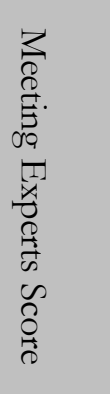 & 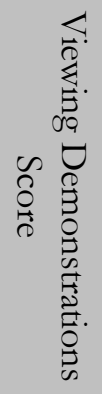 & 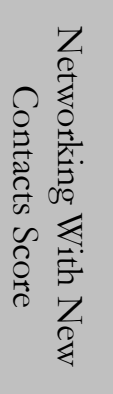 & 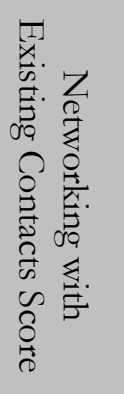 & 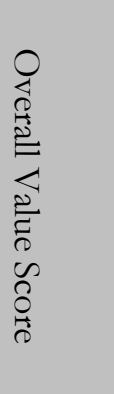 & 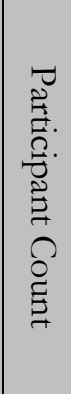 \\
\hline System experiments & 3.19 & 3.13 & 3.81 & 3.16 & 2.91 & 4.00 & 3.16 & 4.16 & 32 \\
\hline Other experiments & 3.47 & 2.82 & 3.88 & 3.12 & 2.82 & 3.82 & 3.24 & 3.71 & 17 \\
\hline T-statistic & -0.79 & 0.84 & -0.19 & 0.11 & 0.23 & 0.49 & -0.22 & 1.25 & \\
\hline $\mathrm{P}$-value & 0.44 & 0.41 & 0.85 & 0.92 & 0.82 & 0.63 & 0.83 & 0.22 & \\
\hline
\end{tabular}

